\title{
What Motivates Innovative Entrepreneurs? Evidence from a Global Field Experiment*
}

\author{
Jorge Guzman \\ Columbia University ${ }^{\dagger}$
}

\author{
Jean Joohyun Oh \\ Columbia University ${ }^{\ddagger}$
}

\author{
Ananya Sen \\ Carnegie Mellon University ${ }^{\S}$
}

\begin{abstract}
Entrepreneurial motivation is important to the process of economic growth. However, evidence on the motivations of innovative entrepreneurs, and how those motivations differ across fundamental characteristics, remains scant. We conduct three interrelated field experiments with the MIT Inclusive Innovation Challenge to study how innovative entrepreneurs respond to messages of money and social impact, and how this varies across gender and culture. We find consistent evidence that women and individuals located in more altruistic cultures are more motivated by social impact messages than money, while men and those in less altruistic cultures are more motivated by money than social impact. The estimates are not driven by differences in the type of company, its size, or other observable characteristics, but instead appear to come from differences in the underlying motivations of innovative entrepreneurs themselves.
\end{abstract}

Keywords: innovation, entrepreneurship, motivations, women, culture

\footnotetext{
${ }^{*}$ Author order alphabetical. We thank the editor, Joshua Gans, the associate editor, and anonymous referees for their valuable suggestions to improve the paper. We are thankful to our field partner, the MIT Inclusive Innovation Challenge (IIC), and particularly to Devin Wardell Cook for her support in this process. We also extend our thanks for their help to Erik Brynjolfsson, Seth Carnahan, Dan Elfenbein, Benjamin Enke, Shannon Farrelly, Barton Hamilton, Bruce Kogut, Kevin Laws, Lamar Pierce, Susan Young, David Verrill, and Minyuan Zhao, and seminar participants at the Columbia Junior Entrepreneurial Finance and Innovation Workshop, the Academy of Management, the IGL Winter Research Meeting (Amsterdam) and Washington University at St. Louis. This project was supported by the MIT IDE and the Columbia Dean's Junior Faculty Diversity Grant. Kyi Yeung Goh provided outstanding research assistantship. The study is pre-registered at the AEA RCT Registry under AEARCTR-0004125, and approved under the Columbia Instituional Review Board (IRB) protocol number AAAS3430. All errors or omissions are of course our own.

†jorge.guzman@columbia.edu. Uris Hall. 3022 Broadway, New York, NY. 10027

${ }_{\ddagger}^{\ddagger}$ jean.oh@columbia.edu Uris Hall. 3022 Broadway, New York, NY. 10027

§ananyase@andrew.cmu.edu. Hamburg Hall. 4800 Forbes Avenue, Pittsburgh, PA. 15217.
} 


\section{Introduction}

Innovative entrepreneurs are central to the process of economic growth. They create companies that produce novel products and services which in turn increase productivity and aggregate well-being. ${ }^{1}$ However, there is limited evidence on what motivates innovative entrepreneurs to participate in this process. While economic theory has almost solely focused on the profit motive (Schumpeter, 1942; Romer, 1990; Aghion and Howitt, 1992), stories about the motives of successful entrepreneurs often focus instead on the importance of social impact. ${ }^{2}$ In fact, the role of pro-social motivations in economic activity has been gaining increasing relevance in research (Cassar and Meier, 2018) and in the media. ${ }^{3}$ Moreover, there is also a recognition that there are ample differences in the salience of such motivations across fundamental dimensions, such as gender and culture (Croson and Gneezy, 2009; Falk et al., 2018). What motivates innovative entrepreneurs? To what extent do pro-social and profit motivations matter? And how does their relative importance vary across gender and culture?

In this paper, we present large sample evidence from a set of three, pre-registered, interrelated experiments to assess what motivates innovative entrepreneurs, and how their motivations differ across gender and culture. Working with the MIT Inclusive Innovation Challenge (MIT IIC)— a premier competition focused on helping innovative entrepreneurs - we perform randomized messaging experiments encouraging individuals to learn more or apply to the competition. The sample includes more than 14,000 entrepreneurs, pulled from the MIT IIC, AngelList, and from Dunn and Bradstreet. We send each individual a randomly assigned social impact message, money message, or neutral technology-focused message, and interpret their response as evidence on the motivations of innovative entrepreneurs themselves. Following our pre-registration, we focus particularly on relative differences across culture and gender. For all our outcomes, which range from privately clicking on emails or websites to learn more about the competition, to submitting a detailed and time costly application, our results document large and heterogeneous

\footnotetext{
${ }^{1}$ Consistent with the literature, we consider a broad definition of innovation (e.g., spans much beyond 'inventors'). However, only a small portion of entrepreneurship is in fact innovative and has the potential to significantly improve well-being and productivity. See Guzman and Stern (2016) for evidence on skewness in the innovative potential of startups, and Catalini et al. (2019) for an in-depth discussion of the relative importance of innovative entrepreneurship in realized startup growth vis-á-vis other processes (e.g., random growth).

${ }^{2}$ For example, In his Harvard Commencement Address, Bill Gates emphasized how innovation and discoveries should be "applied to reduce inequity". https://news.harvard.edu/gazette/story/2007/06/ remarks-of-bill-gates-harvard-commencement-2007/.

${ }^{3}$ The Economist questions "what companies are for" pointing out how companies are now starting to acknowledge the need to incorporate wider social responsibilities as part of their mandate. See https://www.economist.com/ briefing/2019/08/22/big-business-is-beginning-to-accept-broader-social-responsibilities.
} 
differences in the motivations of innovative entrepreneurs. We find that women and individuals located in more altruistic cultures are more motivated by social impact messages than money, while men and those in less altruistic cultures are more motivated by money than social impact. These differential responses appear to mostly be driven by different responses to the social message, as there is little difference in responses to the money message and neutral technology message. Together, these findings constitute novel insights into the motivations of innovative entrepreneurs, and expand existing research in at least three directions.

First, by studying innovative entrepreneurs, we move beyond the self-employed, which has been the focus of the bulk of prior work on entrepreneurial motivations (Hamilton, 2000; Hurst and Pugsley, 2011). It is important to underline that innovative entrepreneurs represent only a small fraction of new firms (Schoar, 2010; Guzman and Stern, 2016), and entrepreneurial motivations vary by growth intentions (Cassar, 2007). The psychological traits of innovative entrepreneurs also appear to be distinct from other groups (Kerr et al., 2019). Hence, it is questionable whether results from the self-employed translate directly to 'growth oriented' innovative entrepreneurs. We are, to the best of our knowledge, the first study to provide direct evidence on the motivations of innovative entrepreneurs who are pivotal to the growth process.

Second, we expand the set of entrepreneurial motivations under consideration by going beyond the profit motive. Even though there is a booming interest in the economics literature on the 'non-pecuniary' incentives of work (such as the meaning of work (Cassar and Meier, 2018)), the dominant paradigm of innovation and entrepreneurship continues to rely on a model of profit goals leading to investment, innovation, and growth. One exception to this could be the literature on 'social enterprises', where social impact has been documented as an important entrepreneurial motive (e.g., Dacin et al., 2011; Ganguli et al., 2019; Hockerts, 2017). Our results have implications for this literature by bringing in the role of gender and culture. We also contribute to this literature by expanding the role of social impact into the domain of innovative entrepreneurs, who are unique actors in the process of economic growth.

Third, our study also provides novel evidence on entrepreneurial motivations by focusing on (pre-registered) fundamental dimensions of heterogeneity, namely culture and gender. ${ }^{4}$ Prior

\footnotetext{
${ }^{4}$ Empirical evidence also documents important differences in preferences across these dimensions in the general population. Croson and Gneezy (2009) review a large number of experimental studies documenting women have higher pro-social preferences, risk-aversion, and inequality aversion. Similar variation exists across culture: Falk et al. (2018) report wide differences in economic preferences across culture, including time preference, risk preference, and altruism. We believe that such systematic differences would also manifest in the motivations of innovative entrepreneurs, and hence choose to focus on them directly.
} 
studies, in an effort to have a more homogeneous sample, have often focused on males residing in the United States (e.g. Hamilton, 2000). Additionally, while one strand of the literature documents a 'gender gap' in entrepreneurship (Bapna and Ganco, 2018; Howell and Nanda, 2019; Kanze et al., 2018; Ewens and Townsend, 2018; Brooks et al., 2014; Ding et al., 2013; Guzman and Kacperczyk, 2019; Lee and Huang, 2018), this work often makes the implicit assumption that motivations themselves are not different across genders. This assumption has implications for both the theoretical and the econometric approach adopted. Our results provide nuance to these studies, expanding on the important role of culture and demographics in entrepreneurship, which can have broad implications for policy and business strategy. Our results also complement previous studies by providing a better picture of how institutional constraints, messaging, identity, and motivations can lead to "missing entrepreneurs" who might slip through the cracks in the process of innovation.

Empirically, our results also join a growing set of studies using experiments to understand entrepreneurship (Camerer and Lovallo, 1999; Bapna, 2017; Chatterji et al., 2019; Astebro and Hoos, 2016; Ganguli et al., 2019; Lee and Huang, 2018; Boudreau and Lakhani, 2016). One paper close to ours in this set is Ganguli et al. (2019), who study similar social and money messages across 431 'nascent social entrepreneurs' - those who have not paid any salaries or wages or have not had positive operating revenue in the past three months — in the UK. While they focus on the main effects of different messages on firm outcomes, our study focuses on heterogeneous effects on a small set of pre-registered outcomes with the goal of specifically capturing motivations, using a larger sample of more than 14,000 entrepreneurs connected to the innovation process. In areas of overlap, however, their results and ours are roughly consistent.

The remainder of the paper proceeds as follows. Section 2 describes our empirical setting, the MIT Inclusive Innovation Challenge. Section 3 provides details on the experimental design. Section 4 presents the results of our three experiments. Section 5 concludes.

\section{Empirical Setting: The MIT Inclusive Innovation Challenge}

The MIT Inclusive Innovation Challenge (MIT IIC) is a premier global competition run within MIT to help innovation-driven entrepreneurs who are using technology to generate economic opportunity. As Erik Brynjolfsson, the co-founder of the IIC put it, the IIC's motto is "It's not what technology does to us, it's what we do with technology." Thus, the mission of the IIC is 
"to accelerate the success of the changemaking entrepreneurs". Since its launch in 2016, the IIC has generated much economic and social impact itself: the IIC's impact report states that IIC winners currently operate in 43 countries, so far generating $\$ 180$ million in revenue and more than 6,800 jobs (IIC, 2019). Screenshots of the IIC's mission statement and impact report are included in the Appendix (Figure A1).

The global scale and diversity of the IIC makes it an attractive setting to study the motivations of entrepreneurs across culture and gender. In contrast to many other business-plan competitions across universities (including at MIT), the MIT IIC does not focus on companies that are student- or alumni-led or affiliated with MIT in other ways. Rather, the IIC seeks to select early-stage startups beyond the "idea phase" with an innovative component and the potential to grow, independent of any affiliation. The IIC also attracts its fair share of women entrepreneurs, in that $41 \%$ of IIC winners are startups with a woman leader or executive (IIC, 2019). In addition, the IIC works with organizations across five continents to recruit innovative entrepreneurs from more than 150 countries to date, providing us an opportunity to observe a culturally diverse pool of innovative entrepreneurs.

The MIT IIC provides various types of support to its entrepreneurs, including feedback given by judges to all companies that submit an application, large cash prizes that winning companies can use to scale and grow (which total more than $\$ 1$ million annually across all winners), and public recognition at regional and global events for those who win the challenge. To select the IIC winners, expert judges in each region evaluate applications to select 60 companies that will proceed to regional pitch events. 20 regional winners are awarded at these events, who then proceed to the global pitch event where four global winners are announced. Winners in recent years reflect the broad range of innovative entrepreneurship that the MIT IIC focuses on, from AdmitHub, which developed an AI-based messaging tool to help students excel in college, to ftcash, an Indian venture empowering micro-merchants through loans using digital payments.

Because finding innovative startups and encouraging them to apply is no easy task, the MIT IIC devotes substantial effort and resources to marketing and outreach, including a professional website, email marketing campaigns, and outreach events with local partners to encourage companies to apply. We engaged with the IIC in May 2018 and partnered with them for their 2019 competition (which began the following March), by supporting their outreach effort through email campaigns. Our study thus focuses on outreach activities in the time leading up to the 
MIT IIC application deadline.

The application process consists of two stages: a registration stage and an application stage. The registration stage asked interested individuals to perform the small task of registering for the MIT IIC by May 9th. This required creating a user account and filling out a short form, which we estimate takes about 5 minutes. The application stage then asked registrants to submit a full application. The application form was composed of sixteen long-form questions that together amounted to a short business plan ${ }^{5}$, which formed the basis upon which applicants were evaluated in the first round. We estimate that this process of filling out the complete application form would take at least two hours for most applicants. All the teams who had registered but not yet submitted an application had two more weeks after the registration deadline, till May 23rd, to do so.

\section{Experimental Design}

As described in our pre-registration, our experiments sent entrepreneurs email messages encouraging them to apply to the MIT IIC. We emphasized one of three narratives in each of the randomized messages: the opportunity for social impact through the IIC (the social condition), the potential monetary benefits of participating in the IIC (the money condition), or simply the possibility of winning the competition, with an emphasis on technology and innovation (the neutral technology condition). We emailed them in three experiments using four distinct samples. We then assessed responses to each of these three messages across gender and culture. We interpret differences in the estimated rate of response as evidence of differences in the underlying motivations of entrepreneurs themselves.

Our main messages were the following in the email subject and body for each condition, with only slight variations otherwise. ${ }^{6}$

- Social condition

- Subject: Create Greater Shared Prosperity. Register Today for the MIT IIC!

\footnotetext{
5 The application questions covered the company's vision, strategy, impact, competitive advantage, risks, and others. All questions are available at https://www.mitinclusiveinnovation.com/the-challenge/\#toc-application.

${ }^{6}$ Templates for all experiments are provided in the Appendix (Figures A2 - A6). In the design of the emails, we particularly focused on emphasizing different incentives for applying to the IIC while keeping constant any other characteristics, such as template design, general length, general information about the IIC, and links to the website for more information.
} 
- Body: ...Win the opportunity to maximize the difference you are making in the world using tech for good!...

- Money condition

- Subject: More than $\$ 1.6$ Million in Prize Money. Register Today for the MIT IIC!

- Body: ...Win prize money and additional opportunities for funding!...

- Neutral Technology condition

- Subject: Register Today for the MIT IIC!

- Body: ...Win by presenting your innovative tech solutions!...

\subsection{Sample Selection and Randomization}

\subsubsection{Registration Email Experiment}

Our first experiment (the 'registration email experiment') pools together two lists of email addresses, the MIT IIC mailing list and a list of contacts purchased from Dunn and Bradstreet (D\&B). The MIT IIC mailing list contains 9,156 contacts after initial cleaning to remove IIC affiliates, prior winners, and other non-entrepreneur groups. These contacts represent a reasonable set of potential applicants who opted to receive updates on the competition. We appended to this list 3,633 contacts purchased from D\&B that we considered mapped to our definition of innovative entrepreneurs. Specifically, building from Guzman and Stern (2016) on the idea that founding choices can represent innovation and growth intent, we developed a stringent criteria that we think captures reasonably well individuals who are leading young firms built around novel ideas that have the potential to increase economic productivity and well-being (i.e., innovative entrepreneurs). We included all contacts available in the D\&B database that (1) are for profit corporations (in the spirit of Guzman and Stern (2016)) (2) were founded between 2014 and 2019, (3) had between 2 and 50 employees, (4) had a yearly revenue of less than $\$ 2$ million, (5) had a web address, and either of (6a) had as the contact the most senior member of the firm whose job title was either founder, president, $\mathrm{CEO}, \mathrm{COO}$ and is in a 'high tech' industry — which are (i) Manufacturing, (ii) Information Services, and (iii) Professional, Scientific, and Technical Services, or (6b) the contact has the title of CTO or CIO. ${ }^{7}$ We admittedly used our discretion

\footnotetext{
${ }^{7}$ In the Appendix Table A9, we present a series of robustness tests relaxing criteria (1) to include partnerships and not-for-profits, and criteria (6a) to include all industries rather than only these 'high-tech'. We also present
} 
to determine these criteria, but we see several advantages to appending this $\mathrm{D} \& \mathrm{~B}$ list to the MIT IIC contacts for our experiment. In particular, doing so provides us with more variation in geographic coverage (the MIT IIC list is much more international than D\&B), increases the external validity of our estimates to allow for entrepreneurs that are not tied to the IIC, and increases statistical power of our analysis.

For each sample, we randomly assigned individuals to one of the three conditions - social, money, and neutral - using the complete randomization procedure. Table A1(a) and (b) show the summary statistics of pre-treatment observables for the IIC and D\&B sample respectively, and the estimated p-values of two-sided t-tests between observations in each treatment arm. We present balance tests of each sample independently because the pre-treatment observables available to us (and hence the variables on which we test for balance) were different. Table A1(a) shows that the MIT IIC mailing list sample is balanced on the main pre-treatment covariates available to us: gender, age, whether they are in the US, whether they have clicked or opened a prior MIT IIC email, and whether they have previously applied or registered with the IIC. Each treatment group was approximately $33 \%$ female, and $66 \%$ from the U.S. Table A1(b) shows the D\&B sample is also balanced on a number of pre-treatment covariates: gender, altruism, job title of CTO or CIO, company revenue, number of employees, whether they are located in the biggest state in the sample (California), and major industries. ${ }^{8}$

\subsubsection{Registration AngelList Experiment}

Our second experiment (the 'registration AngelList experiment') consists of AngelList newsletter recipients who clicked on the "Learn More" link. AngelList entrepreneurs represent the quintessential growth-oriented founders commonly studied in research, and there is a growing stream of studies using this sample for this reason (e.g., Bernstein et al., 2017; Ewens and Townsend, 2018). On May 2nd, AngelList emailed all subscribers its weekly newsletter, in which it included an announcement about the MIT IIC with a link we had provided to them (Figure A3). We configured a special server at the destination of the URL that randomly showed a version of the IIC website mimicking one of three messages we emailed. Once individuals clicked on any of the links on this landing page, they were directed to the main website and continued results using either criteria (6a) or (6b) separately as well as results using the IIC mailing list only. Our results remain unchanged.

${ }^{8}$ Table A1(c) shows that the treatment groups are also well balanced in the extended D\&B sample, which includes all industries as well as partnerships and not-for-profits. 
their visit as a normal IIC website visitor. ${ }^{9}$ The newsletter resulted in more than 1,196 participants landing on our server. Table A1(d) shows that the samples are balanced on observable measures, including location, days between receiving the email and clicking, and device used. Due to the nature of the data, we could not observe visitor gender.

\subsubsection{Application Experiment}

The final experiment (the 'application experiment') occurred after the registration stage closed on May 9th, when registrants had two weeks to submit a full application. On May 10th, we sampled all individuals who had already registered but had not yet submitted an application.

10 We selected the 802 individuals that met two criteria. First, we required that the individuals did not overlap with our first experiment to avoid contamination across messages. ${ }^{11}$ Second, to guarantee that our analysis would be able to solicit the motivations of actual entrepreneurs, we focused only on individuals who designated themselves as CEOs of their company in the registration form (which was asked explicitly). We used complete randomization to assign these subjects to one of the three treatment groups, social, money, or neutral. Table A1(e) shows that the groups are well balanced with respect to pre-treatment observables including gender, altruism, the region in which they registered, the percentage of the application completed at the time of the first email, award category, for-profit vs. non-profit, number of female employees, and revenue. We sent three waves of emails with slightly varied messages encouraging registrants to apply, two to four days apart during the two weeks leading up to the application deadline.

\subsection{Variable Definitions and Summary Statistics}

\subsubsection{Independent Variables}

We define Female as a binary variable equal to one if a subject's gender is female, and zero if male. We determine the gender of participants as predicted by the online marketing tool or from their first name and country using an online API.

We measure culture by taking advantage of the recent work by Falk et al. (2018) that

\footnotetext{
${ }^{9}$ Due to the nature of the online experiment, we could not randomize visitors ex-ante.

${ }^{10} \mathrm{~A}$ total of 1,889 individuals registered by the registration deadline of May 9th, 2019. Reflecting the global nature of the competition, 662 of the registrants were in Africa, 382 in Asia, 208 in Europe, 332 in Latin America, and 305 in the US or Canada.

${ }^{11}$ It is important to note that the IIC uses a variety of marketing approaches beyond our emails, offline and online. The majority of registrants came from these other channels, giving us a sizable sample non-overlapping with our registration stage experiments.
} 
systematically measures global economic preferences along various dimensions across the world. The data includes nationally representative samples from more than 70 countries who are asked survey questions that relate to economic preferences. We focus on the variable Altruism, which captures the pro-social preferences we seek to measure in our experiment. Altruism is measured by Falk et al. (2018) using two survey items related to donation decisions. On the suggestions of these authors, we aggregate this measure at the U.S. state level by using population weights in the disaggregated data, which provides us with U.S. variation. ${ }^{12}$ For each participant, we match this measure to their location based on their IP address (except for the D\&B sample, for which company location is provided by D\&B). We drop a small number of participants in the altruism regressions whose location could not be identified.

\subsubsection{Outcomes}

Based on data availability and experiment design, we estimate entrepreneurs' interest in our messages through five outcome measures. In the registration email experiment, we use two outcome measures that capture revealed interest from responses to treatment messages, both directly in the email and on the website. Total Clicks, our preferred outcome, represents the total number of times a subject clicks on any of the links on the email or IIC website within the first 72 hours after sending the email. Website Clicks represents the total number of clicks on the website alone, within the first 72 hours. In the registration AngelList experiment, we only randomize between those that actually arrive at our website, and hence focus on the time spent on the website as a measure of interest in the IIC. We define two outcome variables. Time Spent (first visit) represents the duration of a subject's first visit to the website (in seconds), and Time Spent (all visits) is the sum of time spent across all visits within 72 hours of receiving the email. We collected data by tracking each visit on our server and on Google Analytics. Finally, in the application experiment, we measure whether a registrant actually applies to the MIT IIC. We define Has Applied as a binary variable that equals one if a registrant has submitted their application by the application deadline of May 23rd, and zero otherwise. Table 1 presents the summary statistics of each of these variables.

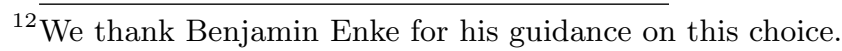




\section{Results}

We now proceed to the centerpiece of our analysis: the differential effects of money and social messages in each of our experiments on motivating entrepreneurs' interest in the MIT Inclusive Innovation Challenge. We analyze each experiment in turn.

\subsection{Registration Email Experiment}

For our registration email experiment, we report the estimated coefficients of Poisson regressions on the count of clicks in Table 2. Columns (1) and (2) report differences in Total Clicks, which is our preferred outcome, while Columns (3) and (4) report differences in Website Clicks. The excluded category is the social message. Finally, we cluster standard errors by country to account for the possibility of within country correlation. Throughout the text, we often translate the coefficient to incidence rate ratio (IRR) for interpretability.

Column (1) reports the variation in Total Clicks for each treatment condition and gender. Our focus is the relative response of men or women to the money message, compared to social. We estimate a positive coefficient of 0.435 for Money, suggesting that men respond more to the money message by $54.5 \%$ with clicks compared to social messages on average $(p=0.002)^{13}$. This effect goes in the opposite direction when we consider women. The interaction of Female and Money has a coefficient of -0.812 that is highly statistically significant. This reflects a net response of -0.377 for women once the main effect is added $(p=0.03)$; that is, women respond with $31.4 \%$ fewer clicks to the money message compared to the social message. We see the same qualitative effects across gender with the neutral message, albeit with slightly smaller effect sizes. The coefficient of 0.172 for Neutral implies that for men, the incidence rate of total clicks increases by $18.7 \%$ in the neutral condition vis-a-vis the social $(p=0.095)$. For women, however, the rate of total clicks decreases by $24.9 \%(p=0.09)$. We also display the aggregate effects in Figure 1 for ease of interpretation.

These estimates indicate striking differences in the responses of men and women to money and social messages, as revealed through their clicks. Women respond more to social messages and less to money messages, while men respond in the opposite way. ${ }^{14}$ This difference between

\footnotetext{
${ }^{13}$ The implied incidence rate ratio is 1.545 , estimated as $\exp (0.435)=1.545$.

${ }^{14}$ This also shows on the extensive margin when we look at the probability of any click as opposed to the number of clicks. In the Appendix Figure A7, we plot the raw probability of any clicks by gender across the money and social treatment to see a similar pattern. Moreover, in column (1) of Table A7, we find qualitatively similar results when we use the probability of clicking as the outcome variable in the regression.
} 
men and women appear to be most strongly driven by their different (and opposing) responses to the social message than the money or neutral message. In particular, women do not seem to treat the money message significantly differently from the neutral condition (statistically and economically). Men seem to slightly prefer money incentives over the neutral technology condition, but this effect is not statistically significant at conventional levels.

Column (2) reports differences in responses across culture, captured by our altruism measure, to the experimental conditions. The results show some interesting parallels with the gender results. The coefficient for Money is positive and significant, with a value of $0.494(p=0.001)$, suggesting our subjects on average respond more to the money message than the social message, but the interaction of Altruism and Money is negative and significant, with a coefficient of $2.190(p<0.001)$. Interpreting this within our data suggests that a subject that moves from the 10th percentile of altruism to the 90th percentile of altruism moves from an estimated $67 \%$ higher relative risk of clicks to the money incentive (compared to the social message), to a $59.8 \%$ lower risk of clicks ( $p=0.001$ and $p<0.001$, respectively). The pattern is similar with the neutral technology condition, though the estimates are less precise and are not significant at conventional levels. The coefficient for the interaction of Altruism and Neutral suggests that, on average, our subjects are less likely to click on the neutral message the higher the level of altruism. ${ }^{15} 16$

The altruism results seem analogous to the gender estimates earlier. We find significant and systematic heterogeneity, where individuals in less altruistic countries respond to the money condition more than social, and those in more altruistic countries show an opposite effect. Moreover, the differences appear to be driven by a differential response to the social condition across cultures. Overall, these estimates suggest that it is important to have a broader conceptualization of the motivations of innovative entrepreneurs that focuses on other motivations beyond profit, and that accounts for fundamental dimensions of heterogeneity such as gender and culture.

\subsubsection{Robustness Tests and Validations}

We now consider a few robustness and validation checks to ensure that our measures adequately capture both motivations and their heterogeneity. First, we ask whether clicks can actually

\footnotetext{
${ }_{15}$ Again, we find qualitatively similar results when we use the probability of clicking as the outcome variable in column (2) of Table A7.

${ }^{16}$ As an additional check, we control for altruism in the gender regressions and for gender in the altruism regressions in Table A5 in the Appendix. We find the results to be qualitatively and quantitatively similar to the baseline estimates described here.
} 
be used as strong enough proxies for the motivations of entrepreneurs to engage in business activity. For instance, there might be a concern that the entrepreneurs' true motivation for social incentives could be short-lived, or that it could simply reflect other elements of their personal identity beyond being an entrepreneur. In Table 3, we carry out an exercise similar to Bapna and Ganco (2018) and consider whether total clicks and email clicks in our data actually predict registration. ${ }^{17}$ To do so, we estimate Logit regressions with the dependent variable being a binary indicator of whether a participant has registered by the registration deadline, and the independent variable the individual response in clicks on the email, the website, or both. Column (1) shows a coefficient of 0.201 for total clicks, implying that an additional click on either the email or website is associated with a $22 \%$ increase in the likelihood to register. Column (2) shows a similarly high coefficient for website clicks. An additional click on an email is correlated with a $25 \%$ higher likelihood of registering. Finally, Column (3) shows the highly significant relationship between number of email clicks and registration with a similar magnitude. We interpret these results as strong evidence that individuals' responses to emails are reflective of their underlying entrepreneurial motivations.

Next, we consider the validity of our measure of altruism within its broader economic context. Given that altruism is measured at the regional level, one potential concern is that altruism is correlated with other regional characteristics such as economic conditions and institutional constraints, which in turn affect entrepreneurs' funding availability and needs. In Table A2, we investigate a number of country-level characteristics using data from the World Bank's World Development Indicators such as GDP per capita, which would be a proxy for overall levels of development, and consider how they relate to our measure of altruism. ${ }^{18}$ The estimates from bivariate OLS regressions show that altruism is not correlated in a statistically or economically significant way with any of the World Bank measures we include: female education, $\log$ (GDP per capita), Gini coefficient, labor force participation, and $\log$ (health expenditure per capita). ${ }^{19}$

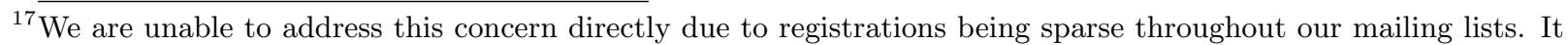
is important to keep in mind that the MIT IIC has a large outreach program with regional partners across the world, well beyond the mailing lists we have access to.

${ }^{18}$ We also present additional robustness checks in Table A6 of the Appendix to show that all our results (across experiments) are robust to controlling for GDP per capita.

${ }^{19}$ We also use '(positive) reciprocity' as an alternative measure of culture to ensure robustness of our results in columns (3)-(8) of Table A7 in the Appendix. Falk et al. (2018) use two measures to arrive at an estimate of reciprocity based on the willingness of individuals to return a favor. While not a perfect proxy, this measure of 'pro-sociality' in culture could be related to the sense of giving back to society. It has a correlation coefficient of 0.7 with the altruism measure. The results are qualitatively similar while quantitatively slightly smaller relative to the altruism measure. This is in line with our logic of using the altruism measure which might capture the culture of 'creating shared prosperity' better.
} 
Finally, in Table A8, we show how male and female entrepreneurs are not systematically different in their relevant observables across samples which provides additional credibility to our findings.

\subsection{Registration AngelList Experiment}

We report the results of our registration AngelList experiment in Table 4. Columns (1) and (2) report differences in the response rate of individuals in our AngelList experiment. These regressions report OLS estimates of the time spent during the first visit (Column (1)) and across all visits (Column (2)). We focus on all visits as our preferred outcome but highlight the fact that the main results are qualitatively the same across columns. Consistent with the results of our registration email experiment, we observe a positive coefficient for the money message, but a negative and significant coefficient for the interaction of money and altruism. On average, individuals who see the money message stay on the website 237 seconds longer across all visits than those who see the social message. However, they spend 850 seconds less on the website for each point increase in the level of altruism. Considering the same range of values as in the registration email experiment (for comparability), an individual at the 10th percentile of altruism would stay 244 seconds more on the website in response to the money message (compared to the social message), while a person in the 90th percentile of altruism would remain 309 seconds less in the money condition than the social condition. We see largely similar patterns for the neutral condition vs. the social condition. While there was no statistically significant difference at the 10th percentile of altruism $(p=0.4)$, an individual at the 90th percentile of altruism was expected to spend 696 seconds less on the website in the neutral condition compared to the $\operatorname{social}(p=0.001)$.

These AngelList results replicates our baseline results with a highly relevant sample of entrepreneurs. We believe this consistency provides strong evidence of the validity of our results, and, more generally, of the importance of heterogeneity in entrepreneurial motivations across cultures.

\subsection{Application Experiment}

Finally, we move to the application stage experiment. As mentioned before, we randomize our messages to companies who have incurred the low cost of registering but have yet to undertake the time intensive task of filling out a lengthy application form and actually applying to the IIC. Columns (3) and (4) of Table 4 report the results. The regressions are Logit models with 
control variables from our balance table as controls in the regression specification to improve precision of estimates. ${ }^{20} 21$

The results are remarkably similar to the registration experiments. Column (3) presents results for gender. The coefficient for money is positive and significant, with a value of 0.676 , suggesting men are $96.5 \%$ more likely to apply under the money condition than the social condition. However, the interaction of money and female is again negative and significant, with a coefficient value of -0.954 . That is, while men have a stronger response to the money message, women are $24.3 \%$ less likely to respond to the money message compared to the social one. Once again, we see similar results when comparing the neutral message to the social: men are $85 \%$ more likely to apply in the neutral message, while women are $32.8 \%$ less likely.

Column (4) reports the treatment effects across culture. We estimate a positive coefficient of 0.278 for the money message on average $(p=0.16)$ and a negative coefficient of -1.431 for the interaction of altruism and money $(p=0.01)$. These coefficients imply that an entrepreneur in the 10th percentile of altruism of our registration sample would be $33.7 \%$ more likely to apply to the IIC (if registered) with the money message, while an entrepreneur in the 90th percentile would be $47.3 \%$ more likely to do so with the social message. Comparing to the neutral message, subjects on average were $37 \%$ more likely to apply when they received the neutral message than the social message, and we see the same change in the direction of the effect as we increase in altruism. The effect varies when we compare the 10th and 90th percentiles of altruism. Subjects in less altruistic countries were $37.5 \%$ more likely to apply with the neutral message than the social message, while those in more altruistic countries were $11.9 \%$ less likely to do so. ${ }^{22}$

These results are reassuring in that we find consistent evidence across all three experiments. There exist consistent differences by gender and altruism in entrepreneurs' responses across the three experiments, even as we move to high cost activities and focus on the startup CEOs themselves. Furthermore, these results appear to be particularly driven by a differential response to the social condition. The motives of 'high growth' innovative entrepreneurs seem more nuanced and complex than existing theory allows.

\footnotetext{
${ }^{20}$ These variables include Award Category, which is a categorical variable that indicates which of the four categories a subject has registered, and For-profit, a binary variable that equals one if a registrant indicated her startup as a for-profit organization. We also control for the Number of female employees in a subject's organization, whether the company serves marginalized populations and if they have any employees above the age of sixty.

${ }^{21}$ For robustness, we test the effect using Probit and OLS regressions, as well as alternative measures for determining whether the registrant is the CEO of the company. These results are reported in Tables A3 and A4.

${ }^{22}$ Like in the previous analysis, we highlight how female and male CEOs were similar across many characteristics as reported in Table A8.
} 


\subsection{Alternative Explanation}

The randomization of the messaging, pre-registration of our heterogeneous treatment effects and consistent results across the three experiments provide us confidence in our estimates. However, we briefly discuss a potential alternative explanation of our results. One alternative explanation of the gender differences is that innovative entrepreneurs could be engaging in sense-making and behaving strategically. For example, women entrepreneurs might respond more to the social message because they want to signal their fit to the IIC, as opposed to follow their 'sincere' underlying motivations. While strategic behavior is possible, it is unlikely to be driving our results in part due to the broad range of our experimental outcomes. Strategic incentives would be absent, in particular, during the registration stage where clicking on the email and/or website is a spontaneous response, and is carried out privately, as far as the subjects are concerned. Thus, consistent results between application and click behaviors lend support to underlying motivations driving the results as opposed to strategic thinking. We also carry out (unreported) exploratory analysis to find that it is indeed the more socially motivated women entrepreneurs applying in the social condition by the heterogeneity in our effects. We gauge "sincere" pro-social motivation by analyzing whether women from more altruistic regions respond more to the social message. Sub-sample analysis points in that direction qualitatively confirming our hypothesis, though the resulting small sample size lacks precision.

\section{Conclusion}

Entrepreneurial motivation is central to the process of economic growth. We performed three interrelated experiments with the MIT Inclusive Innovation Challenge to investigate what motivates innovative entrepreneurs to register and apply. Our results show large, systematically heterogeneous effects across our sample of entrepreneurs: women and individuals located in more altruistic cultures are more motivated by social impact messages than money, while men and those in less altruistic cultures are more motivated by money than social impact. These results highlight the importance of heterogeneous incentives in the choices of innovative entrepreneurs. A significant amount of research has studied the environmental characteristics that promote or hinder entrepreneurship, such as the institutions that protect the profit motive (e.g. patents), and the structural inequalities that preclude certain groups from engaging in innovation. But much less is known about the preferences and motivations of entrepreneurs themselves, and their 
variation across demographics and culture. Our results provide an initial step toward investigating the role of different human motivations that impact in the entrepreneurial process. How these motivations are created and shaped, as well as what can be done to influence them, is a central question for future research, with implications for generating greater shared prosperity.

Our findings could help partially explain disparities in entrepreneurship. Differing motivations could lead to inequities in what entrepreneurs pursue, how they pitch their commitment to their startup, and who is funded. For example, innovative entrepreneurs often pitch to investors like venture capitalists for funding. Given that most venture capitalists operate on the profit motive, women entrepreneurs' relative emphasis on pro-social motivations might hinder their likelihood of receiving funding.

From a policy perspective, our results also have implications for the design of interventions aimed at fostering innovative entrepreneurship. Interestingly, the heterogeneity we found might suggest an important trade-off in the design of entrepreneurship policies and programs: seeking to connect fairly well across different groups might not motivate any group particularly well, while focusing on one particular approach to motivate entrepreneurship (e.g., money) might systematically drive away some groups. We view the outcomes of tailored messages, as well as the trade-offs highlighted in such a process, as important topics for follow-on studies in our agenda.

Finally, from a managerial perspective, our results emphasize the important role of identity and individuality for developing strategic advantages at the early stages of the firm. Gans et al. (2019), for example, emphasize the importance of identity in allowing innovative entrepreneurs to find a defensible position from which to build their entrepreneurial strategies. Our work shows that motivations (and not only skills or experiences) constitute an important component of identity and, presumably, how entrepreneurial competitive advantage is shaped. 


\section{References}

Aghion, P. and Howitt, P. (1992). A Model of Growth Through Creative Destruction. Econometrica, 60(2):323-351.

Astebro, T. B. and Hoos, F. (2016). The effects of a training program to encourage social entrepreneurship. HEC Paris Research Paper No. SPE-2016-1128.

Bapna, S. (2017). Complementarity of signals in early-stage equity investment decisions: Evidence from a randomized field experiment. Management Science, 65(2):933-952.

Bapna, S. and Ganco, M. (2018). Gender gaps in equity crowdfunding: Evidence from a randomized field experiment. Available at SSRN 3263533.

Bernstein, S., Korteweg, A., and Laws, K. (2017). Attracting Early-Stage Investors: Evidence from a Randomized Field Experiment. The Journal of Finance, 72(2):509-538.

Boudreau, K. J. and Lakhani, K. R. (2016). Innovation experiments: researching technical advance, knowledge production, and the design of supporting institutions. Innovation Policy and the Economy, 16(1):135-167.

Brooks, A. W., Huang, L., Kearney, S. W., and Murray, F. E. (2014). Investors prefer entrepreneurial ventures pitched by attractive men. Proceedings of the National Academy of Sciences, 111(12):4427-4431.

Camerer, C. and Lovallo, D. (1999). Overconfidence and excess entry: An experimental approach. American economic review, 89(1):306-318.

Cassar, G. (2007). Money, Money, Money? A Longitudinal Investigation of Entrepreneur Career Reasons, Growth Preferences and Achieved Growth. Entrepreneurship and Regional Development, 19(1):89-107.

Cassar, L. and Meier, S. (2018). Nonmonetary Incentives and the Implications of Work as a Source of Meaning. Journal of Economic Perspectives, 32(3):215-238.

Catalini, C., Guzman, J., and Stern, S. (2019). Passive versus active growth: Evidence from founder choices and venture capital investment. MIT Working Paper. 
Chatterji, A., Delecourt, S., Hasan, S., and Koning, R. (2019). When does advice impact startup performance? Strategic Management Journal, 40(3):331-356.

Croson, R. and Gneezy, U. (2009). Gender Differences in Preferences. Journal of Economic Literature, 47(2):448-474.

Dacin, M. T., Dacin, P. A., and Tracey, P. (2011). Social Entrepreneurship: A Critique and Future Directions. Organization Science, 22:1203-1213.

Ding, W. W., Murray, F., and Stuart, T. E. (2013). From bench to board: Gender differences in university scientists' participation in corporate scientific advisory boards. Academy of Management Journal, 56(5):1443-1464.

Ewens, M. and Townsend, R. (2018). Are early stage investors biased against women? Journal of Financial Economics.

Falk, A., Becker, A., Dohmen, T., Enke, B., Huffman, D., and Sunde, U. (2018). Global evidence on economic preferences. The Quarterly Journal of Economics, 133(4):1645-1692.

Ganguli, I., Le Coq, C., and Huysentruyt, M. (2019). Do nascent social entrepreneurs respond to rewards? a field experiment on motivations in a grant competition. Working Paper.

Gans, J., Scott, E., and Stern, S. (2019). Entrepreneurial Strategy.

Guzman, J. and Kacperczyk, A. O. (2019). Gender gap in entrepreneurship. Research Policy, 48(7):1666-1680.

Guzman, J. and Stern, S. (2016). The State of American Entrepreneurship: New Estimates of the Quantity and Quality of Entrepreneurship for 15 US States, 1988-2014. Working Paper 22095, National Bureau of Economic Research.

Hamilton, B. (2000). Does Entrepreneurship Pay? An Empirical Analysis of the Returns to Self-Employment. Journal of Political Economy, 108(3):604-631.

Hockerts, K. (2017). Determinants of social entrepreneurial intentions. Entrepreneurship Theory and Practice, 41(1):105-130.

Howell, S. and Nanda, R. (2019). Networking frictions in venture capital, and the gender gap in entrepreneurship. Harvard Business School Entrepreneurial Management Working Paper, 19-105. 
Hurst, E. and Pugsley, B. W. (2011). What Do Small Businesses Do? Working Paper 17041, National Bureau of Economic Research.

IIC (2019). The MIT IIC 2019 Impact Report.

Kanze, D., Huang, L., Conley, M. A., and Higgins, E. T. (2018). We ask men to win and women not to lose: Closing the gender gap in startup funding. Academy of Management Journal, 61(2):586-614.

Kerr, S. P., Kerr, W. R., and Dalton, M. (2019). Risk attitudes and personality traits of entrepreneurs and venture team members. Proceedings of the National Academy of Sciences.

Lee, M. and Huang, L. (2018). Gender bias, social impact framing, and evaluation of entrepreneurial ventures. Organization Science, 29(1):1-16.

Romer, P. M. (1990). Endogenous technological change. Journal of political Economy, 98(5, Part 2):S71-S102.

Schoar, A. (2010). The Divide between Subsistence and Transformational Entrepreneurship. Innovation Policy and the Economy, 10:57-81.

Schumpeter, J. A. (1942). Capitalism, Socialism and Democracy. Routledge. 
Table 1: Summary Statistics

\begin{tabular}{|c|c|c|c|c|c|}
\hline & $\begin{array}{c}(1) \\
\text { Mean }\end{array}$ & $\begin{array}{c}(2) \\
\text { Std. Dev. }\end{array}$ & $\begin{array}{l}(3) \\
\text { Min. }\end{array}$ & $\begin{array}{c}(4) \\
\text { Max. }\end{array}$ & $\begin{array}{c}(5) \\
\text { Observations }\end{array}$ \\
\hline \multicolumn{6}{|l|}{ Independent Variables } \\
\hline Altruism & -0.043 & 0.341 & -0.939 & 0.906 & 75 \\
\hline Female Recipients (Registration) & 0.295 & 0.456 & 0 & 1 & 12,511 \\
\hline Female Recipients (Application) & 0.249 & 0.432 & 0 & 1 & 802 \\
\hline \multicolumn{6}{|c|}{ Registration Stage Outcomes: Email Experiment } \\
\hline Number of Website Clicks & 0.114 & 1.185 & 0 & 67 & 12,511 \\
\hline Number of Email Clicks & 0.048 & 0.490 & 0 & 28 & 12,511 \\
\hline \multicolumn{6}{|c|}{ Registration Stage Outcomes: AngelList Experiment } \\
\hline Time Spent (first visit) & 70.778 & 137.51 & 0 & 828 & 1,196 \\
\hline Time Spent (all visits) & 558.46 & 3157.09 & 0 & 73188 & 1,196 \\
\hline \multicolumn{6}{|l|}{ Application Stage Outcomes } \\
\hline Applications & 0.379 & 0.485 & 0 & 1 & 802 \\
\hline
\end{tabular}


Table 2: Registration Round - Main effects on Clicks

\begin{tabular}{|c|c|c|c|c|}
\hline VARIABLES & $\begin{array}{c}(1) \\
\text { Total Clicks }\end{array}$ & $\begin{array}{c}(2) \\
\text { Total Clicks }\end{array}$ & $\begin{array}{c}(3) \\
\text { Website Clicks }\end{array}$ & $\begin{array}{c}(4) \\
\text { Website Clicks }\end{array}$ \\
\hline Money & $\begin{array}{c}0.435^{* * *} \\
(0.137)\end{array}$ & $\begin{array}{c}0.494^{* * *} \\
(0.153)\end{array}$ & $\begin{array}{l}0.404^{*} \\
(0.210)\end{array}$ & $\begin{array}{c}0.389 * * * \\
(0.145)\end{array}$ \\
\hline Neutral & $\begin{array}{l}0.172^{*} \\
(0.103)\end{array}$ & $\begin{array}{c}0.117 \\
(0.159)\end{array}$ & $\begin{array}{c}0.109 \\
(0.144)\end{array}$ & $\begin{array}{r}-0.0571 \\
(0.183)\end{array}$ \\
\hline Female & $\begin{array}{c}0.342^{* * *} \\
(0.111)\end{array}$ & & $\begin{array}{c}0.434^{* * *} \\
(0.124)\end{array}$ & \\
\hline Female x Money & $\begin{array}{c}-0.812^{* * *} \\
(0.224)\end{array}$ & & $\begin{array}{c}-0.855^{* * *} \\
(0.321)\end{array}$ & \\
\hline Female x Neutral & $\begin{array}{c}-0.458^{* *} \\
(0.202)\end{array}$ & & $\begin{array}{c}-0.647^{* * * *} \\
(0.204)\end{array}$ & \\
\hline Altruism & & $\begin{array}{c}0.764 \\
(0.786)\end{array}$ & & $\begin{array}{c}0.631 \\
(0.823)\end{array}$ \\
\hline Altruism x Money & & $\begin{array}{c}-2.190^{* * *} \\
(0.277)\end{array}$ & & $\begin{array}{c}-2.452^{* * * *} \\
(0.280)\end{array}$ \\
\hline Altruism x Neutral & & $\begin{array}{l}-0.679 \\
(0.812)\end{array}$ & & $\begin{array}{l}-0.586 \\
(1.062)\end{array}$ \\
\hline Observations & 12,511 & 10,950 & 12,511 & 10,950 \\
\hline Estimated \% Difference in Click Rate & (vs. Social): & ence Rate Ra & & \\
\hline Female / High Altruism : Money & $-31.4 \%$ & $-59.8 \%$ & $-36.3 \%$ & $-69.4 \%$ \\
\hline Female / High Altruism : Neutral & $-24.9 \%$ & $-27.3 \%$ & $-41.6 \%$ & $-35.1 \%$ \\
\hline Men / Low Altruism : Money & $54.5 \%$ & $67.0 \%$ & $49.7 \%$ & $50.7 \%$ \\
\hline Men / Low Altruism : Neutral & $18.7 \%$ & $13.1 \%$ & $11.5 \%$ & $-5.1 \%$ \\
\hline
\end{tabular}

Robust standard errors clustered by country in parentheses. ${ }^{* * *} p<0.01{ }^{* *} p<0.05,{ }^{*} p<0.1$. The empirical model is a quasi-maximum likelihood (QMLE) Poisson model with the total number of clicks on email links and the IIC website in column (1) and (2), and the number of IIC website clicks in columns (3) and (4). The unit of observation is the individual recipient. Controls include a dummy indicating whether the recipient was in the IIC or Dunn and Bradstreet list, whether the recipient was a registrant or applicant to the IIC in prior years, and the 'member rating' assigned by marketing tool based on prior activity. The reduction in observations in columns (2) and (4) is due to altruism values not being available in the GPS dataset for a few countries. Estimated percent differences in total clicks show the Incidence Rate Ratio minus one. High and low altruism compare the 90th and 10th percentiles of the altruism measure. Magnitudes are computed with the social treatment as the base. The first two rows compute this for females in columns (1) and (3)and for high altruism in (2) and (4). The first row is a comparison of money vs. social while the second is for neutral vs. social. The analogous calculations are made for males and low altruism in rows (3) and (4). 
Table 3: Registration Round - Do Clicks Matter? Correlations with Registration

(1) (2) (3)

VARIABLES Registered After Registered After Registered After

Total Clicks $\quad 0.201^{* * *}$

Website Clicks

$0.227^{* * *}$

$(0.0619)$

Email Clicks

$0.222^{* * *}$

$(0.0527)$

Observations $\quad 12,511 \quad 12,511 \quad 12,511$

Robust standard errors clustered by country in parentheses. ${ }^{* * *} p<0.01, * * p<0.05, *$ $p<0.1$. The empirical model is a Logit model with whether the individual entity registered after the email campaign as the dependent variable. The independent variables of interest are total clicks (sum of email link clicks and website clicks) in column (1), only the number of clicks on the IIC website in column (2), and only the number of email link clicks in column (3). 
Table 4: Main Estimates for AngelList Newsletter and Application Experiment

\begin{tabular}{|c|c|c|c|c|}
\hline VARIABLES & $\begin{array}{c}\text { AngelList } \\
(1) \\
\text { Time Spent (first visit) }\end{array}$ & $\begin{array}{c}\text { AngelList } \\
(2) \\
\text { Time Spent (all visits) }\end{array}$ & $\begin{array}{l}\text { Application Stage } \\
\qquad(3) \\
\text { Applied to IIC }\end{array}$ & $\begin{array}{c}\text { Application Stage } \\
\qquad(4) \\
\text { Applied to IIC }\end{array}$ \\
\hline Money & $\begin{array}{c}12.56 \\
(11.27)\end{array}$ & $\begin{array}{l}236.9^{*} \\
(132.1)\end{array}$ & $\begin{array}{c}0.676^{* * *} \\
(0.259)\end{array}$ & $\begin{array}{c}0.278 \\
(0.199)\end{array}$ \\
\hline Neutral & $\begin{array}{c}7.621 \\
(8.989)\end{array}$ & $\begin{array}{c}-43.60 \\
(55.99)\end{array}$ & $\begin{array}{c}0.615^{* * *} \\
(0.205)\end{array}$ & $\begin{array}{l}0.312^{*} \\
(0.183)\end{array}$ \\
\hline Female & & & $\begin{array}{c}1.102^{* * *} \\
(0.335)\end{array}$ & \\
\hline Female $\times$ Money & & & $\begin{array}{c}-0.954^{* *} \\
(0.467)\end{array}$ & \\
\hline Female $\times$ Neutral & & & $\begin{array}{c}-1.013^{* * *} \\
(0.390)\end{array}$ & \\
\hline Altruism & $\begin{array}{c}40.29 * * * \\
(15.00)\end{array}$ & $\begin{array}{c}1,191^{* * *} \\
(250.9)\end{array}$ & & $\begin{array}{c}1.003^{* *} \\
(0.408)\end{array}$ \\
\hline Altruism $\times$ Money & $\begin{array}{c}-59.51^{* *} \\
(29.12)\end{array}$ & $\begin{array}{c}-850.3^{* *} \\
(325.5)\end{array}$ & & $\begin{array}{c}-1.431^{* *} \\
(0.576)\end{array}$ \\
\hline Altruism $\times$ Neutral & $\begin{array}{c}-62.75^{* * *} \\
(23.40)\end{array}$ & $\begin{array}{c}-1,017^{* * *} \\
(207.1)\end{array}$ & & $\begin{array}{l}-0.684 \\
(0.516)\end{array}$ \\
\hline Observations & 1,128 & 1,128 & 802 & 711 \\
\hline R-squared & 0.008 & 0.008 & - & - \\
\hline Estimated Difference in Outcome & (vs. Social): & & & \\
\hline Female / High Altruism : Money & $-25.6 \mathrm{sec}$ & -309 sec. & $-24.3 \%$ & $-47.3 \%$ \\
\hline Female / High Altruism : Neutral & $-32.7 \mathrm{sec}$ & -696 sec. & $-32.8 \%$ & $-11.9 \%$ \\
\hline Men / Low Altruism : Money & $13.1 \mathrm{sec}$ & 244 sec. & $96.5 \%$ & $33.7 \%$ \\
\hline Men / Low Altruism : Neutral & $8.2 \mathrm{sec}$ & -34.8 sec. & $85.0 \%$ & $37.5 \%$ \\
\hline
\end{tabular}

Robust standard errors clustered by country in parentheses. ${ }^{* * *} p<0.01,{ }^{* *} p<0.05,{ }^{*} p<0.1$. The empirical model is a OLS model with the time spent (in seconds) in the first visit and total time spent (in seconds) in column (1) and (2) as the dependent variable. We include date fixed effects in (1) and (2). The empirical model is a Logit model with whether the company has applied in columns (3) and (4). In column (3) and (4) we control for which category they are registered in, whether they are for-profit, whether any employees over age 60, whether they serve marginalized populations and number of female employees $(\log )$. The unit of observation is the individual registrant. The difference in observations in columns (3) and (4) is due to altruism values not being available in the GPS dataset for a few countries. For estimated differences, we compare high and low altruism using the 90th and 10th percentiles of the altruism measure from the registration round sample for comparability. Estimated percent differences in total clicks in columns (3) and (4) show the Incidence Rate Ratio minus one. Magnitudes are computed with the social treatment as the base. The first two rows compute this for females in column (3) and for high altruism in (1), (2) and (4). The first row is a comparison of money vs. social while the second is for neutral vs. social. The analogous calculations are made for males and low altruism in rows (3) and (4). 
Figure 1: Registration Stage Email Results

(a) Gender

Registration Email: Response by Gender

Percent Difference in Rate of Total Clicks

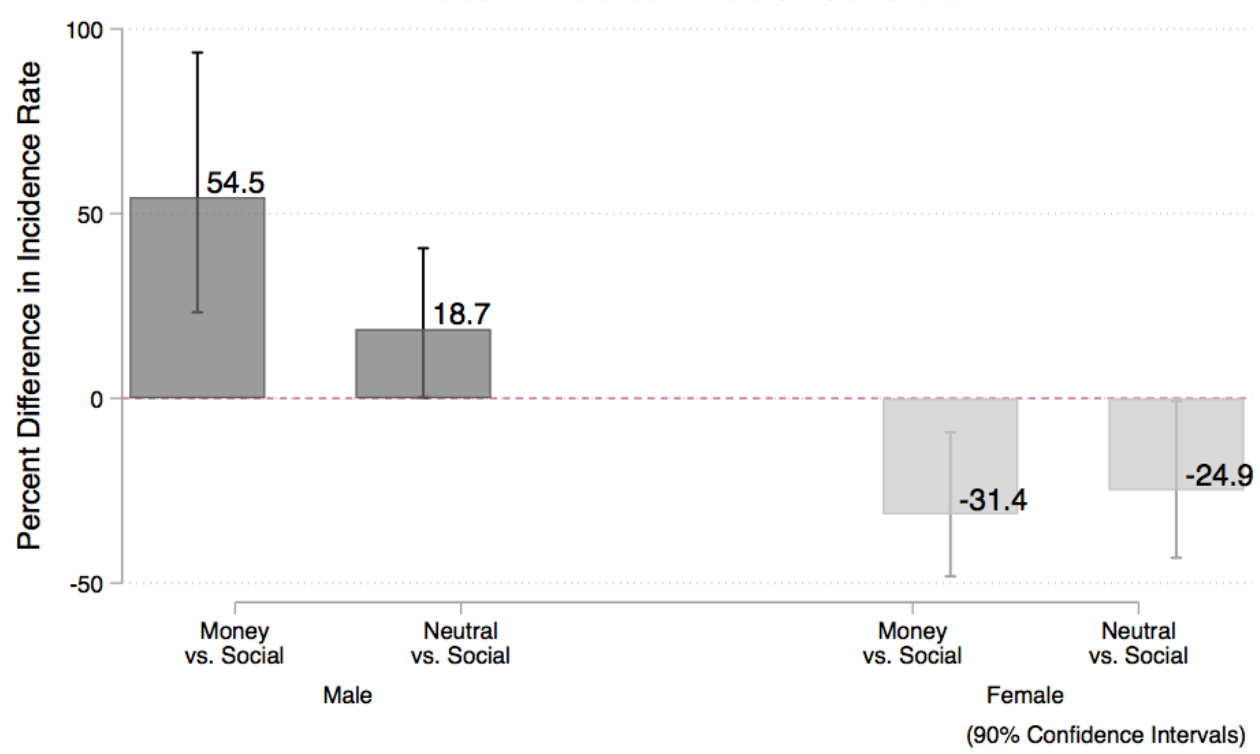

(b) Culture

Registration Email: Response by Altruism

Percent Difference in Rate of Total Clicks

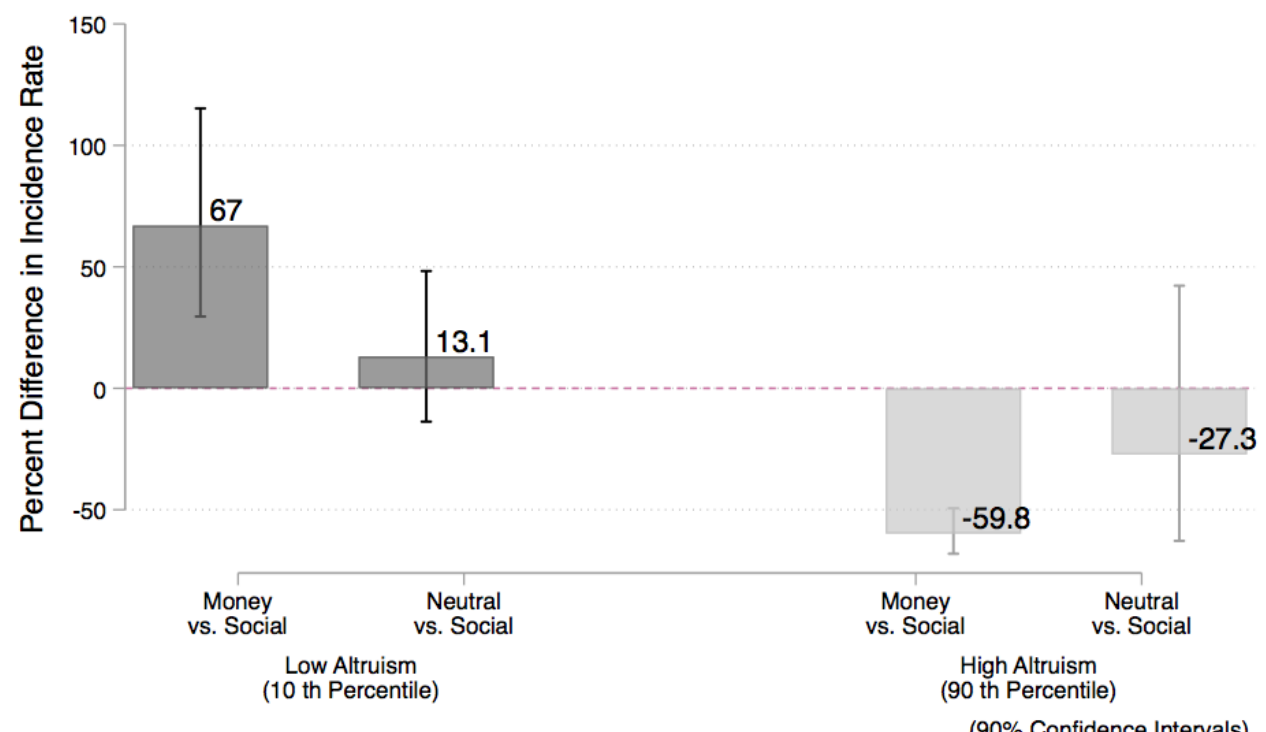


Appendix 
Table A1: Balance Test For Each Experimental Sample

(a) Balance Test for the IIC Mailing List Sample

\begin{tabular}{|c|c|c|c|c|c|c|c|c|c|}
\hline \multirow[b]{2}{*}{ Variable } & \multicolumn{2}{|c|}{ (1) Money } & \multicolumn{2}{|c|}{ (2) Social } & \multicolumn{2}{|c|}{ (3) Neutral } & $(1)-(2)$ & (1)-(3) & $(2)-(3)$ \\
\hline & Mean & SD & Mean & SD & Mean & SD & \multicolumn{3}{|c|}{ P-value } \\
\hline Female & 0.33 & 0.47 & 0.34 & 0.47 & 0.33 & 0.47 & 0.67 & 0.66 & 0.39 \\
\hline Altruism & 0.18 & 0.28 & 0.19 & 0.27 & 0.19 & 0.27 & 0.91 & 0.56 & 0.63 \\
\hline U.S. & 0.66 & 0.47 & 0.67 & 0.47 & 0.66 & 0.47 & 0.85 & 0.57 & 0.46 \\
\hline Age $18-34$ & 0.55 & 0.50 & 0.56 & 0.50 & 0.54 & 0.50 & 0.65 & 0.47 & 0.24 \\
\hline Age $35-54$ & 0.24 & 0.43 & 0.24 & 0.43 & 0.25 & 0.43 & 0.96 & 0.46 & 0.43 \\
\hline Age 55- & 0.17 & 0.38 & 0.17 & 0.37 & 0.17 & 0.38 & 0.60 & 0.84 & 0.74 \\
\hline Ever Opened & 0.84 & 0.37 & 0.85 & 0.36 & 0.83 & 0.37 & 0.40 & 0.70 & 0.22 \\
\hline Ever Clicked & 0.44 & 0.50 & 0.45 & 0.50 & 0.45 & 0.50 & 0.73 & 0.85 & 0.88 \\
\hline Prior Registrant & 0.27 & 0.45 & 0.27 & 0.44 & 0.27 & 0.44 & 0.59 & 0.56 & 0.96 \\
\hline Prior Applicant & 0.10 & 0.30 & 0.10 & 0.30 & 0.09 & 0.29 & 0.97 & 0.42 & 0.40 \\
\hline $\mathrm{N}$ & 2969 & & 2959 & & 2950 & & & & \\
\hline
\end{tabular}

(b) Balance Test for Dunn \& Bradstreet Sample

\begin{tabular}{|c|c|c|c|c|c|c|c|c|c|}
\hline \multirow[b]{2}{*}{ Variable } & \multicolumn{2}{|c|}{ (1) Money } & \multicolumn{2}{|c|}{ (2) Social } & \multicolumn{2}{|c|}{ (3) Neutral } & $(1)-(2)$ & $(1)-(3)$ & $(2)-(3)$ \\
\hline & Mean & $\mathrm{SD}$ & Mean & SD & Mean & $\mathrm{SD}$ & \multicolumn{3}{|c|}{ P-value } \\
\hline Female & 0.21 & 0.41 & 0.22 & 0.41 & 0.19 & 0.39 & 0.79 & 0.38 & 0.20 \\
\hline Altruism & 0.46 & 0.24 & 0.44 & 0.25 & 0.45 & 0.23 & 0.17 & 0.72 & 0.11 \\
\hline Title - CTO, CIO & 0.12 & 0.33 & 0.11 & 0.31 & 0.12 & 0.33 & 0.57 & 0.71 & 0.38 \\
\hline Revenue (USD Mil) & 0.28 & 0.34 & 0.27 & 0.33 & 0.28 & 0.35 & 0.62 & 0.66 & 0.30 \\
\hline \# of Employees & 5.01 & 5.52 & 5.05 & 5.55 & 4.94 & 5.03 & 0.85 & 0.73 & 0.65 \\
\hline State - CA & 0.27 & 0.45 & 0.29 & 0.45 & 0.30 & 0.46 & 0.42 & 0.21 & 0.41 \\
\hline NAICS - Manufacturing & 0.15 & 0.36 & 0.16 & 0.37 & 0.16 & 0.36 & 0.38 & 0.68 & 0.60 \\
\hline NAICS - Information & 0.14 & 0.34 & 0.13 & 0.33 & 0.14 & 0.35 & 0.45 & 0.71 & 0.24 \\
\hline NAICS - Professional, Science, Tech Services & 0.65 & 0.48 & 0.64 & 0.48 & 0.62 & 0.49 & 0.67 & 0.20 & 0.25 \\
\hline $\mathrm{N}$ & 1193 & & 1200 & & 1240 & & & & \\
\hline
\end{tabular}

(c) Balance Test for Dunn \& Bradstreet Extended Sample

\begin{tabular}{|c|c|c|c|c|c|c|c|c|c|}
\hline \multirow[b]{2}{*}{ Variable } & \multicolumn{2}{|c|}{ (1) Money } & \multicolumn{2}{|c|}{ (2) Social } & \multicolumn{2}{|c|}{ (3) Neutral } & $(1)-(2)$ & $(1)-(3)$ & $(2)-(3)$ \\
\hline & Mean & $\mathrm{SD}$ & Mean & $\mathrm{SD}$ & Mean & $\mathrm{SD}$ & \multicolumn{3}{|c|}{ P-value } \\
\hline Female & 0.23 & 0.42 & 0.23 & 0.42 & 0.22 & 0.41 & 0.75 & 0.36 & 0.22 \\
\hline Altruism & 0.45 & 0.24 & 0.45 & 0.25 & 0.45 & 0.25 & 0.46 & 0.92 & 0.52 \\
\hline Title - Founder & 0.29 & 0.45 & 0.29 & 0.45 & 0.29 & 0.45 & 0.97 & 0.60 & 0.57 \\
\hline Title - CEO & 0.38 & 0.49 & 0.38 & 0.49 & 0.37 & 0.48 & 0.83 & 0.51 & 0.38 \\
\hline Title - CTO, COO, CIO & 0.09 & 0.29 & 0.09 & 0.28 & 0.08 & 0.28 & 0.37 & 0.18 & 0.65 \\
\hline Revenue (USD Mil) & 0.24 & 0.31 & 0.24 & 0.31 & 0.25 & 0.32 & 0.72 & 0.41 & 0.24 \\
\hline \# of Employees & 4.81 & 4.98 & 4.88 & 5.13 & 4.99 & 5.32 & 0.59 & 0.16 & 0.39 \\
\hline State - CA & 0.18 & 0.39 & 0.18 & 0.39 & 0.19 & 0.39 & 0.93 & 0.74 & 0.67 \\
\hline Type - Nonprofit & 0.02 & 0.14 & 0.03 & 0.16 & 0.03 & 0.16 & 0.25 & 0.25 & 0.99 \\
\hline Type - Partnership & 0.02 & 0.14 & 0.02 & 0.15 & 0.02 & 0.14 & 0.21 & 1.00 & 0.21 \\
\hline NAICS - Professional, Science, Tech Services & 0.25 & 0.43 & 0.25 & 0.43 & 0.24 & 0.43 & 1.00 & 0.78 & 0.78 \\
\hline NAICS - Finance, Insurance & 0.07 & 0.26 & 0.07 & 0.26 & 0.07 & 0.26 & 0.65 & 0.61 & 0.95 \\
\hline NAICS - Manufacturing & 0.06 & 0.23 & 0.06 & 0.25 & 0.06 & 0.24 & 0.23 & 0.41 & 0.70 \\
\hline NAICS - Information & 0.05 & 0.22 & 0.05 & 0.21 & 0.05 & 0.23 & 0.48 & 0.63 & 0.23 \\
\hline $\mathrm{N}$ & 3268 & & 3277 & & 3271 & & & & \\
\hline
\end{tabular}


Table A1: Balance Test For Each Experimental Sample (Continued)

(d) Balance Test for AngelList Newsletter Sample

\begin{tabular}{|c|c|c|c|c|c|c|c|c|c|}
\hline \multirow[b]{2}{*}{ Variable } & \multicolumn{2}{|c|}{ (1) Money } & \multicolumn{2}{|c|}{ (2) Social } & \multicolumn{2}{|c|}{ (3) Neutral } & $(1)-(2)$ & $(1)-(3)$ & (2)-(3) \\
\hline & Mean & SD & Mean & SD & Mean & SD & \multicolumn{3}{|c|}{$\mathrm{P}$-value } \\
\hline Altruism & 0.18 & 0.30 & 0.21 & 0.28 & 0.20 & 0.29 & 0.12 & 0.39 & 0.49 \\
\hline North America \& EU & 0.80 & 0.40 & 0.76 & 0.43 & 0.79 & 0.41 & 0.17 & 0.73 & 0.30 \\
\hline Days to Click & 0.46 & 0.73 & 0.44 & 0.70 & 0.47 & 0.76 & 0.59 & 0.95 & 0.55 \\
\hline Device - Apple & 0.55 & 0.50 & 0.54 & 0.50 & 0.59 & 0.49 & 0.83 & 0.19 & 0.12 \\
\hline Device - Desktop & 0.51 & 0.50 & 0.50 & 0.50 & 0.51 & 0.50 & 0.83 & 1.00 & 0.83 \\
\hline $\mathrm{N}$ & 388 & & 410 & & 398 & & & & \\
\hline
\end{tabular}

(e) Balance Test for Application Stage Sample

\begin{tabular}{|c|c|c|c|c|c|c|c|c|c|}
\hline \multirow[b]{2}{*}{ Variable } & \multicolumn{2}{|c|}{ (1) Money } & \multicolumn{2}{|c|}{ (2) Social } & \multicolumn{2}{|c|}{ (3) Neutral } & $(1)-(2)$ & (1)-(3) & $(2)-(3)$ \\
\hline & Mean & SD & Mean & SD & Mean & SD & \multicolumn{3}{|c|}{ P-value } \\
\hline Female & 0.21 & 0.41 & 0.25 & 0.43 & 0.26 & 0.44 & 0.23 & 0.19 & 0.88 \\
\hline Altruism & -0.05 & 0.38 & -0.05 & 0.35 & -0.07 & 0.35 & 0.96 & 0.40 & 0.39 \\
\hline Region - Africa & 0.35 & 0.48 & 0.41 & 0.49 & 0.42 & 0.49 & 0.13 & 0.13 & 0.95 \\
\hline Region - Asia & 0.21 & 0.41 & 0.17 & 0.38 & 0.20 & 0.40 & 0.25 & 0.69 & 0.46 \\
\hline Region - Europe & 0.09 & 0.29 & 0.09 & 0.28 & 0.10 & 0.30 & 0.92 & 0.61 & 0.52 \\
\hline Region - Latin America & 0.16 & 0.37 & 0.15 & 0.36 & 0.14 & 0.35 & 0.78 & 0.51 & 0.69 \\
\hline Region - US \& Canada & 0.14 & 0.35 & 0.15 & 0.36 & 0.14 & 0.34 & 0.75 & 0.76 & 0.52 \\
\hline Application \% Completed & 0.16 & 0.31 & 0.12 & 0.28 & 0.16 & 0.32 & 0.19 & 0.97 & 0.20 \\
\hline Award Category - Financial Inclusion & 0.18 & 0.38 & 0.17 & 0.37 & 0.19 & 0.39 & 0.72 & 0.81 & 0.54 \\
\hline Award Category - income Growth \& Job Creation & 0.29 & 0.45 & 0.32 & 0.47 & 0.29 & 0.45 & 0.52 & 0.91 & 0.45 \\
\hline Award Category - Skills Development \& Opportunity Matching & 0.30 & 0.46 & 0.34 & 0.47 & 0.29 & 0.45 & 0.36 & 0.70 & 0.19 \\
\hline Award Category - Technology Access & 0.22 & 0.42 & 0.18 & 0.38 & 0.23 & 0.42 & 0.14 & 0.83 & 0.09 \\
\hline For-Profit & 0.90 & 0.31 & 0.87 & 0.33 & 0.89 & 0.32 & 0.37 & 0.72 & 0.59 \\
\hline Log(\# of Female Employees) & 0.86 & 1.36 & 0.93 & 0.60 & 0.87 & 0.56 & 0.48 & 0.99 & 0.19 \\
\hline Revenue (USD Mil) & 32.48 & 533.76 & 0.36 & 2.77 & 0.17 & 1.02 & 0.32 & 0.32 & 0.26 \\
\hline Any Employee Over Age 60 & 0.12 & 0.33 & 0.16 & 0.37 & 0.12 & 0.33 & 0.16 & 0.95 & 0.18 \\
\hline Serves Indigenous Population & 0.48 & 0.50 & 0.48 & 0.50 & 0.46 & 0.50 & 0.99 & 0.62 & 0.62 \\
\hline $\mathrm{N}$ & 277 & & 319 & & 281 & & & & \\
\hline
\end{tabular}


Table A2: Altruism and Development Indicators

\begin{tabular}{|c|c|c|c|c|c|}
\hline VARIABLES & $\begin{array}{c}(1) \\
\text { Altruism }\end{array}$ & $\begin{array}{c}(2) \\
\text { Altruism }\end{array}$ & $\begin{array}{c}(3) \\
\text { Altruism }\end{array}$ & $\begin{array}{c}(4) \\
\text { Altruism }\end{array}$ & $\begin{array}{c}(5) \\
\text { Altruism }\end{array}$ \\
\hline Female education & $\begin{array}{c}0.00144 \\
(0.00877)\end{array}$ & & & & \\
\hline Log GDP Per Capita & & $\begin{array}{c}0.00105 \\
(0.0163)\end{array}$ & & & \\
\hline Gini Coefficient & & & $\begin{array}{c}0.00250 \\
(0.00586)\end{array}$ & & \\
\hline Labor Force Participation & & & & $\begin{array}{c}-0.00301 \\
(0.00388)\end{array}$ & \\
\hline Log Health Expenditure Per Capita & & & & & $\begin{array}{c}-0.0068 \\
(0.0254)\end{array}$ \\
\hline Observations & 41 & 75 & 68 & 76 & 76 \\
\hline R-squared & 0.001 & 0.000 & 0.003 & 0.008 & 0.001 \\
\hline
\end{tabular}

Standard errors in parentheses. ${ }^{* * *} p<0.01,{ }^{* *} p<0.05,{ }^{*} p<0.1$. The empirical model is a bivariate OLS with country level altruism as the dependent variable. The unit of observation is at the country level. 
Table A3: Application Round - Robustness and Alternative Measure

$(1)$

(Probit)
$(2)$

(OLS)
(3)

(Threshold 1) (Threshold 2) (Threshold 3)

\section{VARIABLES}

Has Applied
(4)

Has Applied Has Applied

$\begin{array}{lccccc}\text { Money } & 0.410^{* * *} & 0.147^{* *} & 0.924^{* * *} & 0.856^{* * *} & 0.806^{* * *} \\ & (0.158) & (0.0576) & (0.289) & (0.290) & (0.283) \\ \text { Neutral } & 0.373^{* * *} & 0.133^{* * *} & 0.711^{* * *} & 0.663^{* *} & 0.635^{* *} \\ & (0.124) & (0.0446) & (0.263) & (0.268) & (0.256) \\ \text { Female } & 0.680^{* * *} & 0.250^{* * *} & 1.175^{* * *} & 1.075^{* *} & 1.074^{* *} \\ & (0.207) & (0.0799) & (0.441) & (0.443) & (0.425) \\ \text { Female x Money } & -0.585^{* *} & -0.213^{*} & -1.115^{* *} & -1.009^{*} & -0.966^{*} \\ & (0.290) & (0.114) & (0.560) & (0.559) & (0.530) \\ \text { Female x Neutral } & -0.621^{* *} & -0.229^{* *} & -0.954^{*} & -0.936^{*} & -0.882^{*} \\ & (0.242) & (0.0938) & (0.525) & (0.519) & (0.520)\end{array}$

\begin{tabular}{llllll}
\hline Observations & 802 & 802 & 647 & 668 & 685
\end{tabular}

Robust standard errors in parentheses clustered by registration date. $* * * p<0.01, * * p<0.05$, $^{*} p<0.1$. The empirical model is a Probit in (1), OLS in (2) and Logit in (3)-(5) with whether the company has applied as the dependent variable. We control for which category they are registered in, whether they for profit, number of female employees and revenue. Columns (1) and (2) are alternate specifications for the baseline application experiment results. Columns (3)-(5) use the Stata 'strdist' measure to match CEO names using 3 thresholds (distance of less than 5,6 and 7). 
Table A4: Application Round - Robustness and Alternative Measure

\begin{tabular}{|c|c|c|c|c|c|}
\hline VARIABLES & $\begin{array}{c}(1) \\
\text { (Probit) } \\
\text { Has Applied }\end{array}$ & $\begin{array}{c}(2) \\
\text { (OLS) } \\
\text { Has Applied }\end{array}$ & $\begin{array}{c}(3) \\
\text { (Threshold 1) } \\
\text { Has Applied }\end{array}$ & $\begin{array}{c}(4) \\
\text { (Threshold 2) } \\
\text { Has Applied }\end{array}$ & $\begin{array}{c}(5) \\
\text { (Threshold 3) } \\
\text { Has Applied }\end{array}$ \\
\hline Money & $\begin{array}{c}0.167 \\
(0.121)\end{array}$ & $\begin{array}{c}0.0607 \\
(0.0455)\end{array}$ & $\begin{array}{c}0.545^{* *} \\
(0.223)\end{array}$ & $\begin{array}{c}0.492^{* *} \\
(0.230)\end{array}$ & $\begin{array}{c}0.435^{*} \\
(0.226)\end{array}$ \\
\hline Neutral & $\begin{array}{l}0.189^{*} \\
(0.113)\end{array}$ & $\begin{array}{c}0.0686 \\
(0.0430)\end{array}$ & $\begin{array}{c}0.457^{* *} \\
(0.215)\end{array}$ & $\begin{array}{l}0.403^{*} \\
(0.224)\end{array}$ & $\begin{array}{l}0.386^{*} \\
(0.213)\end{array}$ \\
\hline Altruism & $\begin{array}{c}0.596^{* *} \\
(0.242)\end{array}$ & $\begin{array}{c}0.211^{* *} \\
(0.0861)\end{array}$ & $\begin{array}{l}0.907^{*} \\
(0.491)\end{array}$ & $\begin{array}{c}0.782 \\
(0.506)\end{array}$ & $\begin{array}{l}0.805^{*} \\
(0.471)\end{array}$ \\
\hline Altruism $\times$ Money & $\begin{array}{c}-0.862^{* *} \\
(0.350)\end{array}$ & $\begin{array}{c}-0.312^{* *} \\
(0.128)\end{array}$ & $\begin{array}{c}-1.449^{* *} \\
(0.678)\end{array}$ & $\begin{array}{c}-1.351^{*} \\
(0.698)\end{array}$ & $\begin{array}{c}-1.348^{* *} \\
(0.670)\end{array}$ \\
\hline Altruism $\times$ Neutral & $\begin{array}{l}-0.397 \\
(0.306)\end{array}$ & $\begin{array}{l}-0.136 \\
(0.113)\end{array}$ & $\begin{array}{l}-0.407 \\
(0.667)\end{array}$ & $\begin{array}{l}-0.223 \\
(0.676)\end{array}$ & $\begin{array}{l}-0.358 \\
(0.627)\end{array}$ \\
\hline Observations & 711 & 711 & 575 & 591 & 604 \\
\hline
\end{tabular}

Robust standard errors in parentheses clustered by registration date. ${ }^{* * *} p<0.01,{ }^{* *} p<0.05$, $^{*} p<0.1$. The empirical model is a Probit in (1), OLS in (2) and Logit in (3)-(5) with whether the company has applied as the dependent variable. We control for which category they are registered in, whether they for profit, number of female employees and revenue. Columns (1) and (2) are alternate specifications for the baseline application experiment results. Columns (3)-(5) use the Stata 'strdist' measure to match CEO names using 3 thresholds (distance of less than 5,6 and 7). 
Table A5: Robustness Check - Controlling for Gender in Altruism Specifications and Vice Versa

\begin{tabular}{|c|c|c|c|c|c|c|}
\hline VARIABLES & $\begin{array}{c}\text { Registration E-mail } \\
(1) \\
\text { Total Clicks } \\
\end{array}$ & $\begin{array}{c}\text { Registration E-mail } \\
(2) \\
\text { Total Clicks } \\
\end{array}$ & $\begin{array}{c}\text { Registration E-mail } \\
(3) \\
\text { Website Clicks } \\
\end{array}$ & $\begin{array}{c}\text { Registration E-mail } \\
(4) \\
\text { Website Clicks } \\
\end{array}$ & $\begin{array}{l}\text { Application Stage } \\
\text { (5) } \\
\text { Applied to IIC }\end{array}$ & $\begin{array}{c}\text { Application Stage } \\
(6) \\
\text { Applied to IIC }\end{array}$ \\
\hline Money & $\begin{array}{c}0.494^{* * *} \\
(0.149)\end{array}$ & $\begin{array}{c}0.491^{* * *} \\
(0.155)\end{array}$ & $\begin{array}{l}0.433^{*} \\
(0.221)\end{array}$ & $\begin{array}{c}0.388^{* * *} \\
(0.150)\end{array}$ & $\begin{array}{c}0.595^{* *} \\
(0.265)\end{array}$ & $\begin{array}{c}0.281 \\
(0.199)\end{array}$ \\
\hline Neutral & $\begin{array}{c}0.194^{*} \\
(0.107)\end{array}$ & $\begin{array}{c}0.116 \\
(0.161)\end{array}$ & $\begin{array}{c}0.0928 \\
(0.141)\end{array}$ & $\begin{array}{r}-0.0577 \\
(0.187)\end{array}$ & $\begin{array}{c}0.560^{* * *} \\
(0.211)\end{array}$ & $\begin{array}{c}0.302 \\
(0.185)\end{array}$ \\
\hline Female & $\begin{array}{c}0.358^{* * *} \\
(0.110)\end{array}$ & $\begin{array}{l}-0.0375 \\
(0.0942)\end{array}$ & $\begin{array}{c}0.420^{* * *} \\
(0.120)\end{array}$ & $\begin{array}{c}-0.0154 \\
(0.147)\end{array}$ & $\begin{array}{c}1.004^{* * *} \\
(0.379)\end{array}$ & $\begin{array}{c}0.394^{* *} \\
(0.186)\end{array}$ \\
\hline Female x Money & $\begin{array}{c}-0.748^{* * *} \\
(0.193)\end{array}$ & & $\begin{array}{c}-0.756^{* * *} \\
(0.267)\end{array}$ & & $\begin{array}{c}-0.999^{* *} \\
(0.505)\end{array}$ & \\
\hline Female x Neutral & $\begin{array}{c}-0.486^{* *} \\
(0.207)\end{array}$ & & $\begin{array}{c}-0.654^{* * *} \\
(0.223)\end{array}$ & & $\begin{array}{c}-0.904^{* *} \\
(0.432)\end{array}$ & \\
\hline Altruism & $\begin{array}{l}-0.422 \\
(0.698)\end{array}$ & $\begin{array}{c}0.764 \\
(0.787)\end{array}$ & $\begin{array}{l}-0.695 \\
(0.755)\end{array}$ & $\begin{array}{c}0.631 \\
(0.824)\end{array}$ & $\begin{array}{c}0.235 \\
(0.178)\end{array}$ & $\begin{array}{c}0.970^{* *} \\
(0.398)\end{array}$ \\
\hline Altruism x Money & & $\begin{array}{c}-2.186^{* * *} \\
(0.275)\end{array}$ & & $\begin{array}{c}-2.450^{* * *} \\
(0.281)\end{array}$ & & $\begin{array}{c}-1.422^{* *} \\
(0.565)\end{array}$ \\
\hline Altruism x Neutral & & $\begin{array}{l}-0.678 \\
(0.814)\end{array}$ & & $\begin{array}{l}-0.585 \\
(1.066)\end{array}$ & & $\begin{array}{c}-0.693 \\
(0.526)\end{array}$ \\
\hline Observations & 10,950 & 10,950 & 10,950 & 10,950 & 711 & 711 \\
\hline
\end{tabular}

Robust standard errors in parentheses clustered by country. ${ }^{* * *} p<0.01,{ }^{* *} p<0.05,{ }^{*} p<0.1$. Columns (1)-(4) refer to the IIC and Dunn and Bradstreet sample that corresponds to the registration e-mail sample. Columns (5)-(6) consists of the application stage sample. We use the Poisson QMLE model in (1)-(4) and a Logit model in (5)-(6). The unit of observation is the individual recipient. In (1)-(4) controls include a dummy indicating whether the recipient was in the IIC or Dunn and Bradstreet list, whether the recipient was a registrant or applicant to the IIC in prior years, and the 'member rating' assigned by marketing tool based on prior activity. In column (5) and (6) we control for which category they are registered in, whether they are for-profit, whether any employees over age 60, whether they serve marginalized populations and number of female employees (log). 
Table A6: Robustness Check - Controlling for GDP Per Capita

\begin{tabular}{|c|c|c|c|c|c|c|c|c|}
\hline VARIABLES & $\begin{array}{c}\text { Registration E-mail } \\
(1) \\
\text { Total Clicks } \\
\end{array}$ & $\begin{array}{c}\text { Registration E-mail } \\
(2) \\
\text { Total Clicks } \\
\end{array}$ & $\begin{array}{c}\text { Registration E-mail } \\
\text { (3) } \\
\text { Website Clicks } \\
\end{array}$ & $\begin{array}{c}\text { Registration E-mail } \\
(4) \\
\text { Website Clicks } \\
\end{array}$ & $\begin{array}{c}\text { AngelList Sample (First Session) } \\
\text { (5) } \\
\text { Time Spent (first visit) } \\
\end{array}$ & $\begin{array}{c}\text { AngelList Sample (All Sessions) } \\
\text { (6) } \\
\text { Time Spent (all visits) } \\
\end{array}$ & $\begin{array}{c}\text { Application Stage } \\
\text { (7) } \\
\text { Applied to IIC } \\
\end{array}$ & $\begin{array}{c}\text { Application Stage } \\
\text { (8) } \\
\text { Applied to IIC }\end{array}$ \\
\hline Money & $\begin{array}{c}0.451^{* * * *} \\
(0.153)\end{array}$ & $\begin{array}{c}0.493^{* * * *} \\
(0.150)\end{array}$ & $\begin{array}{l}0.386^{*} \\
(0.226)\end{array}$ & $\begin{array}{c}0.387^{* * * *} \\
(0.142)\end{array}$ & $\begin{array}{c}13.45 \\
(11.53)\end{array}$ & $\begin{array}{l}250.1^{*} \\
(137.2)\end{array}$ & $\begin{array}{l}0.655^{* * *} \\
(0.263)\end{array}$ & $\begin{array}{c}0.269 \\
(0.202)\end{array}$ \\
\hline Neutral & $\begin{array}{c}0.132 \\
(0.116)\end{array}$ & $\begin{array}{c}0.109 \\
(0.159)\end{array}$ & $\begin{array}{l}0.0247 \\
(0.135)\end{array}$ & $\begin{array}{l}-0.0681 \\
(0.184)\end{array}$ & $\begin{array}{c}8.369 \\
(9.372)\end{array}$ & $\begin{array}{r}-32.51 \\
(60.83)\end{array}$ & $\begin{array}{c}0.646^{* * * *} \\
(0.212)\end{array}$ & $\begin{array}{c}0.268 \\
(0.181)\end{array}$ \\
\hline Female & $\begin{array}{c}0.333^{* * * *} \\
(0.127)\end{array}$ & & $\begin{array}{c}0.392^{* * * *} \\
(0.142)\end{array}$ & & & & $\begin{array}{c}1.123^{* * * *} \\
(0.353)\end{array}$ & \\
\hline Female x Money & $\begin{array}{c}-0.754^{* * * *} \\
(0.204)\end{array}$ & & $\begin{array}{c}-0.763^{* * * *} \\
(0.281)\end{array}$ & & & & $\begin{array}{c}-0.951^{* * *} \\
(0.482)\end{array}$ & \\
\hline Female $\mathrm{x}$ Neutral & $\begin{array}{c}-0.446^{* * *} \\
(0.227)\end{array}$ & & $\begin{array}{c}-0.628 * * * \\
(0.235)\end{array}$ & & & & $\begin{array}{c}-1.102^{* * * *} \\
(0.396)\end{array}$ & \\
\hline Altruism & & $\begin{array}{c}0.784 \\
(0.773)\end{array}$ & & $\begin{array}{c}0.663 \\
(0.798)\end{array}$ & $\begin{array}{c}43.93^{* * * *} \\
(16.13)\end{array}$ & $\begin{array}{c}1,245^{* * * *} \\
(261.6)\end{array}$ & & $\begin{array}{c}0.936^{* * *} \\
(0.413)\end{array}$ \\
\hline Altruism x Money & & $\begin{array}{c}-2.173^{* * * *} \\
(0.269)\end{array}$ & & $\begin{array}{c}-2.434^{* * * *} \\
(0.267)\end{array}$ & $\begin{array}{c}-61.33^{* * *} \\
(29.64)\end{array}$ & $\begin{array}{c}-877.2^{* * *} \\
(335.2)\end{array}$ & & $\begin{array}{c}-1.423^{* * *} \\
(0.579)\end{array}$ \\
\hline Altruism x Neutral & & $\begin{array}{l}-0.657 \\
(0.812)\end{array}$ & & $\begin{array}{l}-0.556 \\
(1.060)\end{array}$ & $\begin{array}{l}-63.97^{* * * *} \\
(23.84)\end{array}$ & $\begin{array}{c}-1,035^{* * * *} \\
(25,2)\end{array}$ & & $\begin{array}{l}-0.725 \\
(0.519)\end{array}$ \\
\hline $\log$ (GDP Per Capita) & $\begin{array}{c}0.0882 \\
(0.0768)\end{array}$ & $\begin{array}{c}0.0515 \\
(0.0647)\end{array}$ & $\begin{array}{c}0.121 \\
(0.0828)\end{array}$ & $\begin{array}{c}0.0727 \\
(0.0624)\end{array}$ & $\begin{array}{l}4.113 \\
(5.073)\end{array}$ & $\begin{array}{c}60.94 \\
(54.12)\end{array}$ & $\begin{array}{c}-0.0272 \\
(0.0524)\end{array}$ & $\begin{array}{c}-0.0403 \\
(0.0635)\end{array}$ \\
\hline Observations & 11,121 & 10,939 & 11,121 & $\begin{array}{l}10,939 \\
\end{array}$ & 1,128 & 1,128 & 780 & 706 \\
\hline
\end{tabular}

Robust standard errors in parentheses clustered by country. ${ }^{* * *} p<0.01,{ }^{* *} p<0.05,{ }^{*} p<0.1$. Columns (1)-(4) refer to the IIC and Dunn and Bradstreet sample that corresponds to the registration e-mail sample. Columns (5)-(6) consists of the AngelList registration stage sample while (7)-(8) analyzes the application stage sample. The unit of observation is the individual recipient. We use the Poisson QMLE model in (1)-(4), OLS regression in (5)-(6) and a Logit model in (7)-(8). In (1)-(4) controls include a dummy indicating whether the recipient was in the IIC or Dunn and Bradstreet list, whether the recipient was a registrant or applicant to the IIC in prior years, and the 'member rating' assigned by marketing tool based on prior activity. In columns (5)-(6), we include date of click fixed effects. In column (7) and (8) we control for which category they are registered in, whether they are for-profit, whether any employees over age 60 , whether they serve marginalized populations and number of female employees $(\log )$. 
Table A7: Robustness Check - Extensive Margin and Alternative Measure of Culture

\begin{tabular}{|c|c|c|c|c|c|c|c|c|}
\hline VARIABLES & $\begin{array}{c}\text { Registration E-mail } \\
\text { (1) } \\
\text { Has Clicked }\end{array}$ & $\begin{array}{c}\text { Registration E-mail } \\
(2) \\
\text { Has Clicked }\end{array}$ & $\begin{array}{c}\text { Registration E-mail } \\
\text { (3) } \\
\text { Total Clicks }\end{array}$ & $\begin{array}{c}\text { Registration E-mail } \\
\text { (4) } \\
\text { Total Clicks }\end{array}$ & $\begin{array}{c}\text { Registration E-mail } \\
\text { (5) } \\
\text { Total Clicks }\end{array}$ & $\begin{array}{c}\text { Application Stage } \\
\text { (6) } \\
\text { Has Applied }\end{array}$ & $\begin{array}{c}\text { Application Stage } \\
\text { (7) } \\
\text { Has Applied }\end{array}$ & $\begin{array}{c}\text { Application Stage } \\
\text { (8) } \\
\text { Has Applied }\end{array}$ \\
\hline Money & $\begin{array}{c}0.310 \\
(0.212)\end{array}$ & $\begin{array}{c}0.367^{* * *} \\
(0.156)\end{array}$ & $\begin{array}{c}0.186^{*} \\
(0.0977)\end{array}$ & $\begin{array}{c}0.184^{*} \\
(0.100)\end{array}$ & $\begin{array}{c}0.185^{*} \\
(0.0985)\end{array}$ & $\begin{array}{c}0.180 \\
(0.197)\end{array}$ & $\begin{array}{c}0.180 \\
(0.197)\end{array}$ & $\begin{array}{c}0.172 \\
(0.201)\end{array}$ \\
\hline Neutral & $\begin{array}{c}0.136 \\
(0.108)\end{array}$ & $\begin{array}{l}0.0950 \\
(0.104)\end{array}$ & $\begin{array}{c}0.0142 \\
(0.0918)\end{array}$ & $\begin{array}{c}0.0129 \\
(0.0920)\end{array}$ & $\begin{array}{c}0.00940 \\
(0.0912)\end{array}$ & $\begin{array}{c}0.267 \\
(0.213)\end{array}$ & $\begin{array}{c}0.277 \\
(0207)\end{array}$ & $\begin{array}{c}0.225 \\
(0.203)\end{array}$ \\
\hline Female & $\begin{array}{c}0.205 \\
(0.157)\end{array}$ & & & $\begin{array}{c}-0.0390 \\
(0.0940)\end{array}$ & $\begin{array}{c}-0.0398 \\
(0.0949)\end{array}$ & $\begin{array}{l}0.390^{* * *} \\
(0.179)\end{array}$ & & \\
\hline Female x Money & $\begin{array}{c}-0.497^{* * * *} \\
(0.140)\end{array}$ & & & & & & & \\
\hline Female $\mathrm{x}$ Neutral & $\begin{array}{c}-0.435^{* * * *} \\
(0.166)\end{array}$ & & & & & & & \\
\hline Altruism & & $\begin{array}{c}0.600 \\
(0.550)\end{array}$ & & & & & & \\
\hline Altruism x Money & & $\begin{array}{c}-0.700^{* * *} \\
(0.354)\end{array}$ & & & & & & \\
\hline Altruism x Neutral & & $\begin{array}{l}-0.414 \\
(0.400)\end{array}$ & & & & & & \\
\hline Positive Reciprocity & & & $\begin{array}{c}0.286 \\
(1.034)\end{array}$ & $\begin{array}{c}0.287 \\
(1.029)\end{array}$ & $\begin{array}{c}0.300 \\
(1.021)\end{array}$ & $\begin{array}{c}0.917^{* * *} \\
(0.373)\end{array}$ & $\begin{array}{c}0.942^{* * *} \\
(0.388)\end{array}$ & $\begin{array}{c}0.907^{* *} \\
(0.392)\end{array}$ \\
\hline Positive Reciprocity x Money & & & $\begin{array}{c}-2.019^{* * * * *} \\
(0.619)\end{array}$ & $\begin{array}{c}-2.017^{* * * *} \\
(0.620)\end{array}$ & $\begin{array}{c}-2.000^{* * * * *} \\
(0.613)\end{array}$ & $\begin{array}{c}-0.978^{* * *} \\
(0.473)\end{array}$ & $\begin{array}{c}-0.969^{* * *} \\
(0.475)\end{array}$ & $\begin{array}{c}-0.971^{* * *} \\
(0.477)\end{array}$ \\
\hline Positive Reciprocity x Neutral & & & $\begin{array}{l}-0.223 \\
(1.250)\end{array}$ & $\begin{array}{l}-0.223 \\
(1.245)\end{array}$ & $\begin{array}{l}-0.208 \\
(1.238)\end{array}$ & $\begin{array}{l}-0.396 \\
(0.512)\end{array}$ & $\begin{array}{c}-0.399 \\
(0.509)\end{array}$ & $\begin{array}{c}-0.463 \\
(0.504)\end{array}$ \\
\hline Log(GDP Per Capita) & & & & & $\begin{array}{c}0.0326 \\
(0.0573)\end{array}$ & & & $\begin{array}{l}-0.0278 \\
(0.0553)\end{array}$ \\
\hline Observations & 12,511 & 10,950 & 10,950 & 10,950 & 10,939 & 711 & 711 & 706 \\
\hline
\end{tabular}

Robust standard errors in parentheses clustered by country. ${ }^{* * *} p<0.01,{ }^{* *} p<0.05,{ }^{*} p<0.1$. Columns (1)-(2) tests the extensive margin using the dependent variable of whether the recipient clicked on an email link. Columns (3)-(8) use positive reciprocity, instead of altruism, as an alternative measure of a prosocial culture. Columns (1)-(5s) use the IIC and Dunn and Bradstreet sample that corresponds to the registration e-mail sample. Column (6)-(8) consists of the application stage sample. The unit of observation is the individual recipient. We use Logit models in Columns (1)-(2), a Poisson QMLE model in (3)-(5), and a Logit model in (6)-(8). In Columns (1)-(5), controls include a dummy indicating whether the recipient was in the IIC or Dunn and Bradstreet list, whether the recipient was a registrant or applicant to the IIC in prior years, and the 'member rating' assigned by marketing tool based on prior activity. In columns (6)-(8) we control for which category they are registered in, whether they are for-profit, whether any employees over age 60, whether they serve marginalized populations and number of female employees $(\log )$. Columns (4) and (7) also control for whether the recipient is female while columns (5) and (8) control for the GDP Per Capital of the country. 
Table A8: Gender Differences in Observables across Samples

\begin{tabular}{|c|c|c|c|c|c|c|}
\hline \multirow[b]{2}{*}{ Variable } & \multicolumn{2}{|c|}{ (1) Male } & \multicolumn{2}{|c|}{ (2) Female } & \multicolumn{2}{|l|}{$(1)-(2)$} \\
\hline & Mean & $\mathrm{SD}$ & Mean & $\mathrm{SD}$ & P-value & Observations \\
\hline $\mathrm{CIO}$ & 0.0098 & 0.0098 & 0.0067 & 0.081 & 0.48 & 3,610 \\
\hline $\mathrm{CTO}$ & 0.105 & 0.307 & 0.131 & 0.337 & 0.32 & 3,610 \\
\hline New York-California & 0.18 & 0.38 & 0.168 & 0.37 & 0.97 & 12,511 \\
\hline Click Rate & 0.053 & 0.001 & 0.052 & 0.001 & 0.94 & 8,878 \\
\hline Open Rate & 0.333 & 0.17 & 0.328 & 0.261 & 0.987 & 8,878 \\
\hline Prior Applicant & 0.095 & 0.080 & 0.098 & 0.119 & 0.979 & 8,878 \\
\hline $\log ($ Revenue $)$ & 6.37 & 0.30 & 6.08 & 0.53 & 0.63 & 876 \\
\hline Number of College Educated & 1.54 & 0.10 & 1.48 & 0.17 & 0.74 & 766 \\
\hline Word of Mouth & 0.46 & 0.04 & 0.49 & 0.08 & 0.75 & 876 \\
\hline Firm Age & 0.85 & 0.01 & 0.83 & 0.02 & 0.56 & 876 \\
\hline Number of People Over 60 & 0.148 & 0.01 & 0.10 & 0.02 & 0.11 & 876 \\
\hline Serves Marginalized & 0.477 & 0.06 & 0.461 & 0.11 & 0.90 & 876 \\
\hline
\end{tabular}

This Table looks at differences in observables across male and female entrepreneurs across our samples. The first six characteristics come from the IIC or Dunn and Bradstreet lists (or both if available) in the e-mail registration experiment while the last six are drawn from the application experiment. Standard errors for p-values are clustered at regional level (country or US state) to account for within-region correlations. 
Table A9: Registration Round - Robustness with Different D\&B Samples

\begin{tabular}{|c|c|c|c|c|c|c|c|c|}
\hline VARIABLES & $\begin{array}{c}\text { IIC } \\
+ \\
\text { D\&B Extended Sample } \\
(1) \\
\text { Total Clicks }\end{array}$ & $\begin{array}{c}\text { IIC } \\
+ \\
\text { D\&B Extended Sample } \\
(2) \\
\text { Total Clicks }\end{array}$ & $\begin{array}{c}\text { IIC } \\
+ \\
\text { D\&B High-Tech Sample } \\
(3) \\
\text { Total Clicks }\end{array}$ & $\begin{array}{c}\text { IIC } \\
+ \\
\text { D\&B High-Tech Sample } \\
(4) \\
\text { Total Clicks }\end{array}$ & $\begin{array}{c}\mathrm{IC} \\
+ \\
\mathrm{D} \& \mathrm{~B} \text { CTO/CIO Sample } \\
(5) \\
\text { Total Clicks }\end{array}$ & $\begin{array}{c}\mathrm{IC} \\
+ \\
\mathrm{D} \& \mathrm{~B} \text { CTO/CIO Sample } \\
(6) \\
\text { Total Clicks }\end{array}$ & $\begin{array}{c}\text { IIC Sample Only } \\
(7) \\
\text { Total Clicks }\end{array}$ & $\begin{array}{c}\text { IIC Sample Only } \\
(8) \\
\text { Total Clicks }\end{array}$ \\
\hline Money & $\begin{array}{c}0.419^{* * * *} \\
(0.135)\end{array}$ & $\begin{array}{c}0.499^{* * * *} \\
(0.135)\end{array}$ & $\begin{array}{c}0.435^{* * * *} \\
(0.137)\end{array}$ & $\begin{array}{c}0.493^{* * *} \\
(0.153)\end{array}$ & $\begin{array}{c}0.431^{* * * *} \\
(0.143)\end{array}$ & $\begin{array}{c}0.471^{* * *} \\
(0.166)\end{array}$ & $\begin{array}{c}0.431^{* * * *} \\
(0.143)\end{array}$ & $\begin{array}{c}0.469^{* * * *} \\
(0.166)\end{array}$ \\
\hline Neutral & $\begin{array}{l}0.206^{* *} \\
(0.0978)\end{array}$ & $\begin{array}{c}0.112 \\
(0.151)\end{array}$ & $\begin{array}{l}0.172^{*} \\
(0.103)\end{array}$ & $\begin{array}{c}0.118 \\
(0.159)\end{array}$ & $\begin{array}{c}0.145 \\
(0.109)\end{array}$ & $\begin{array}{c}0.105 \\
(0.164)\end{array}$ & $\begin{array}{c}0.145 \\
(0.109)\end{array}$ & $\begin{array}{c}0.105 \\
(0.164)\end{array}$ \\
\hline Female & $\begin{array}{c}0.367^{* * * *} \\
(0.107)\end{array}$ & & $\begin{array}{c}0.342^{2 * * *} \\
(0.111)\end{array}$ & & $\begin{array}{c}0.344^{* * *} \\
(0.112)\end{array}$ & & $\begin{array}{c}0.343^{* * * *} \\
(0.111)\end{array}$ & \\
\hline Female x Money & $\begin{array}{c}-0.764^{* * * *} \\
(0.229)\end{array}$ & & $\begin{array}{c}-0.815^{* * * *} \\
(0.227)\end{array}$ & & $\begin{array}{c}-0.830^{* * * * *} \\
(0.230)\end{array}$ & & $\begin{array}{c}-0.840^{* * * *} \\
(0.230)\end{array}$ & \\
\hline Female $\mathrm{x}$ Neutral & $\begin{array}{c}-0.524^{* * * *} \\
(0.203)\end{array}$ & & $\begin{array}{c}-0.457^{* * *} \\
(0.203)\end{array}$ & & $\begin{array}{c}-0.450^{* * *} \\
(0.204)\end{array}$ & & $\begin{array}{c}-0.458 * * \\
(0.207)\end{array}$ & \\
\hline Altruism & & $\begin{array}{c}0.706 \\
(0.728)\end{array}$ & & $\begin{array}{c}0.762 \\
(0.788)\end{array}$ & & $\begin{array}{c}0.864 \\
(0.834)\end{array}$ & & $\begin{array}{c}0.872 \\
(0.837)\end{array}$ \\
\hline Altruism x Money & & $\begin{array}{c}-2.046^{* * * *} \\
(0.269)\end{array}$ & & $\begin{array}{c}-2.192^{* * * *} \\
(0.277)\end{array}$ & & $\begin{array}{c}-2.372^{* * * *} \\
(0.312)\end{array}$ & & $\begin{array}{c}-2.387^{* * * *} \\
(0.315)\end{array}$ \\
\hline Altruism x Neutral & & $\begin{array}{l}-0.525 \\
(0.680)\end{array}$ & & $\begin{array}{l}-0.669 \\
(0.814)\end{array}$ & & $\begin{array}{l}-0.834 \\
(0.937)\end{array}$ & & $\begin{array}{l}-0.849 \\
(0.948)\end{array}$ \\
\hline Observations & $\begin{array}{ll}18,693 \\
\end{array}$ & 17,132 & 12,258 & $\begin{array}{ll}10,697 \\
\end{array}$ & 9,311 & 7,750 & 8,878 & 7,317 \\
\hline
\end{tabular}

Robust standard errors in parentheses clustered by country. ${ }^{* * *} p<0.01,{ }^{* *} p<0.05, * p<0.1$. The empirical model is a quasi-maximum likelihood (QMLE) Poisson model predicting the total number of clicks on email links. The unit of observation is the individual recipient. Columns (1)-(2) use the IIC sample and D\&B extended sample that includes all industries as well as partnerships and not-for-profits. Columns (3)-(4) use the IIC sample and the D\&B sub-sample of high-tech industries Manufacturing, Information, and Professional, Scientific, and Technical Services - excluding partnerships and not-for-profits. Columns (5)-(6) uses the IIC sample and the D\&B sub-sample of CTO or CIO contacts, also excluding partnerships and not-for-profits. Columns (7)-(8) uses the IIC sample only. Controls include a dummy indicating whether the recipient was in the IIC or D\&B list, whether the recipient was a registrant or applicant to the IIC in prior years, and the 'member rating' assigned by marketing tool based on prior activity. The reduction in observations in columns with interactions with altruism is due to altruism values not being available in the by marketing tool based on prior 
Figure A1: (a) Screenshot of the IIC's Mission Statement

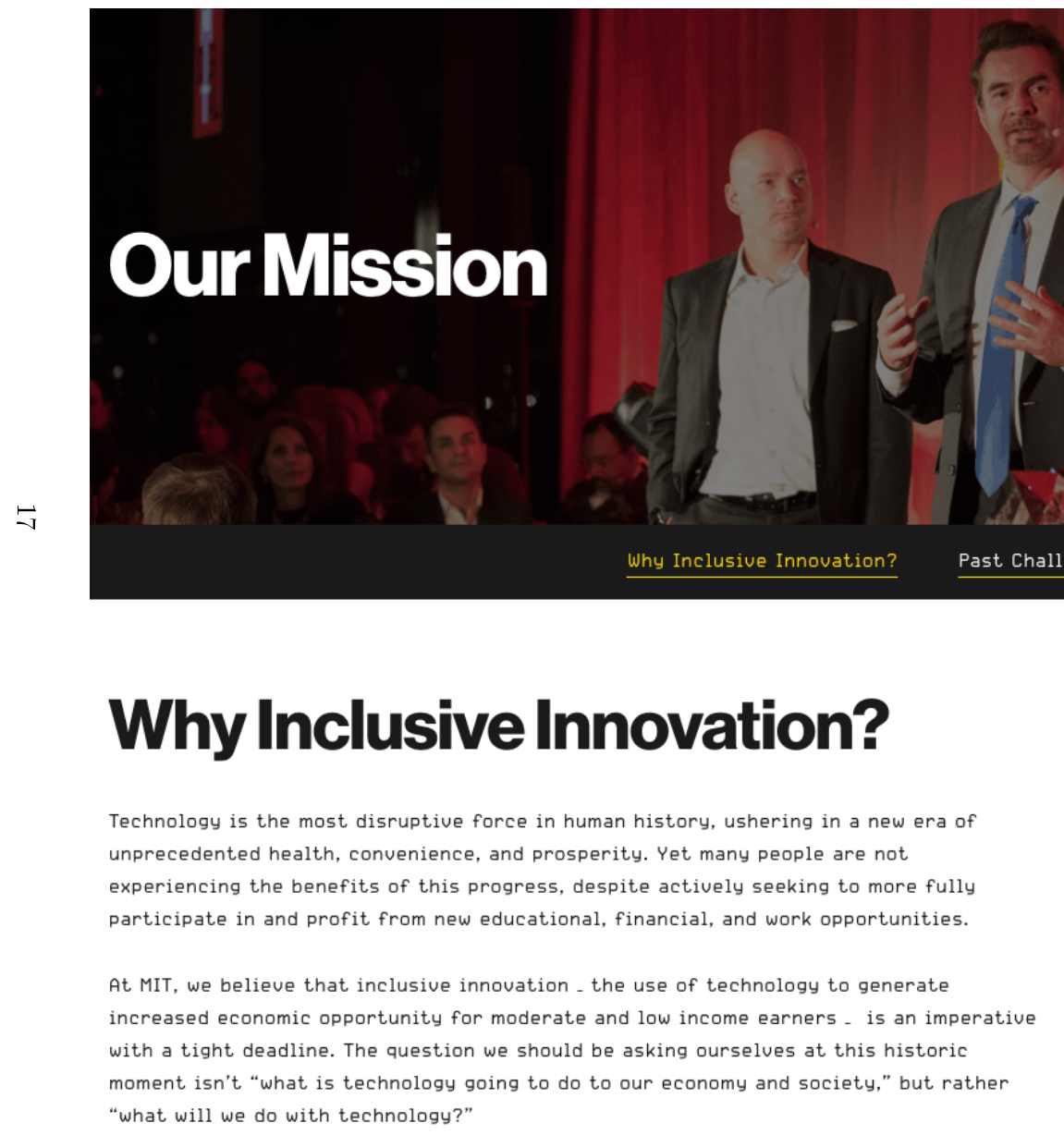

"Let's not bury the lede. The lede is that our world and the state of humanity...is improving overall very quickly because of tech progress."

Andrew McAfee

Co-founder, MIT Inclusive Innovation Challenge

Our vision is an economy that works for all. Our mission is to accelerate the success of the changemaking entrepreneurs that are making that vision a reality, and to drive a solutions-oriented conversation about the future of work. 
The IIC accelerates innovation- driven entrepreneurship for a more inclusive and prosperous economy.

\section{$\$ 178.9 \mathrm{M} \quad 6,800+\$ 1.05 B \quad 283$}

\begin{tabular}{|c|c|c|c|c|}
\hline $\begin{array}{l}\text { ECONOMIC } \\
\text { IMPACT }\end{array}$ & $\begin{array}{l}\text { Cumulative revenue } \\
\text { generated since } \\
2016 \text { by } \\
\text { IIC organizations }\end{array}$ & $\begin{array}{l}\text { Jobs created } \\
\text { since } 2016 \text { by } \\
\text { IIC organizations }\end{array}$ & $\begin{array}{l}\text { Cumulative capital } \\
\text { raised since } \\
2016 \text { by } \\
\text { IIC organizations }\end{array}$ & $\begin{array}{l}\text { New offices } \\
\text { opened in } 2018 \text { by } \\
\text { IIC organizations }\end{array}$ \\
\hline
\end{tabular}

\begin{tabular}{|c|ccc|}
\hline SOCLAL & $356 \mathrm{M}$ & $\mathbf{4 1 \%}$ & $\mathbf{4 3}$ \\
\hline IMPACT" & $\begin{array}{c}\text { Beneficiaries served in } \\
\text { 2018 by IIC } \\
\text { organizations }\end{array}$ & $\begin{array}{c}\text { Female } \\
\text { leaders } \\
\text { executives at IIC } \\
\text { organizations }\end{array}$ & $\begin{array}{c}\text { Number of } \\
\text { countries where IIC } \\
\text { organizations are } \\
\text { operating } \\
\text { in 2019 }\end{array}$ \\
\hline
\end{tabular}

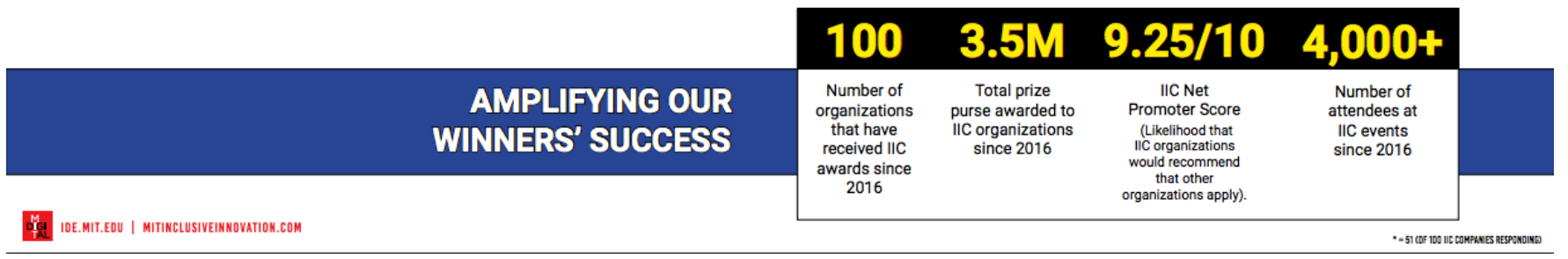


Figure A2: (a) Registration Stage Email Templates - Money Treatment

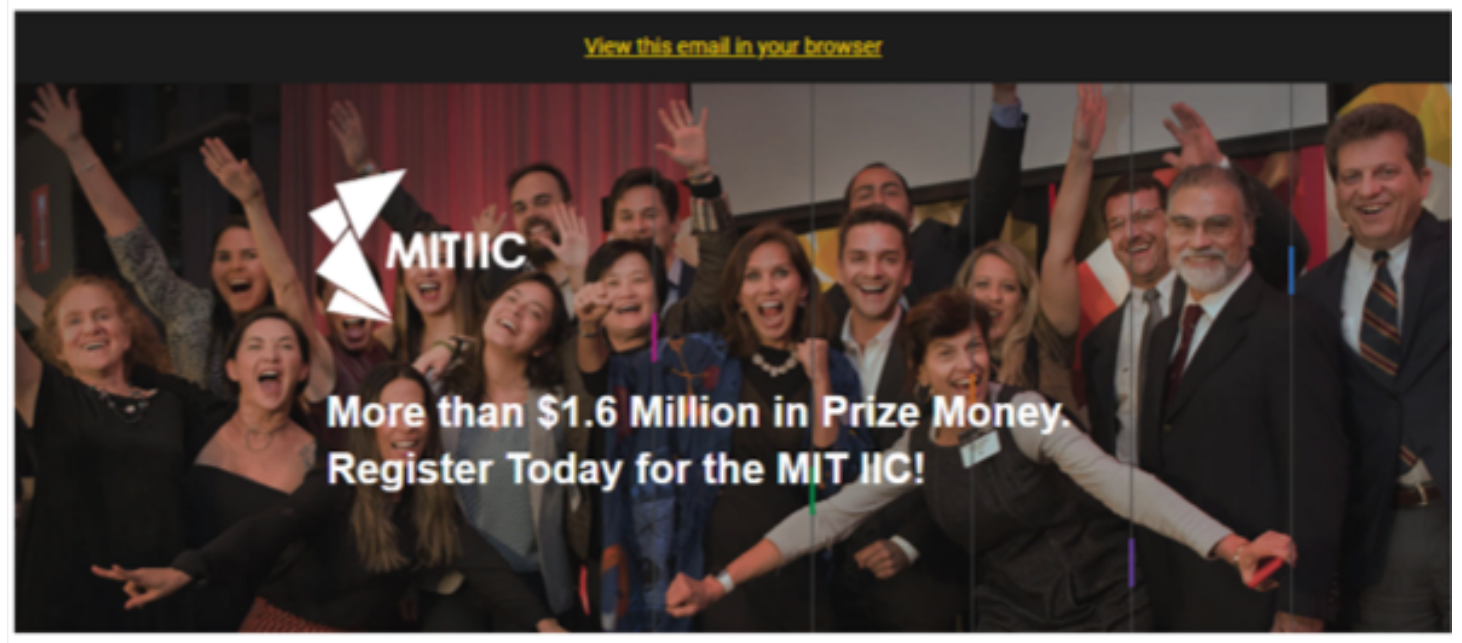

Hi "IFNAME|",

The MIT IIC is seeking innovative entrepreneurs with solutions to our 2019 Challenge. Win prize money and additional opportunities for funding!

The IIC is the flagship program of the MIT Initiative on the Digital Economy, awarding more than $\$ 1$ million annually to entrepreneurs who are using technology to create innovative solutions to global challenges. Global Winners will receive a $\$ 250,000$ prize from IIC as well as access to potential investors. In the last three years, the IIC has committed more than $\$ 3.5$ million in funding to winners. View past winners.

We collaborate with like-minded organizations in five regions to select and celebrate sixty Regional Finalists from across the globe. Twenty Regional Winners will be invited to the Global Grand Prize Gala at MIT, where four Global Winners will be announced. Learn more about the llC.

\section{Registration Closes May 9.}

REGISTER NOW

\section{(†) (ㅇ) (ㅇ) (ㅇ)


Figure A2: (b) Registration Stage Email Templates - Social Treatment

to me.

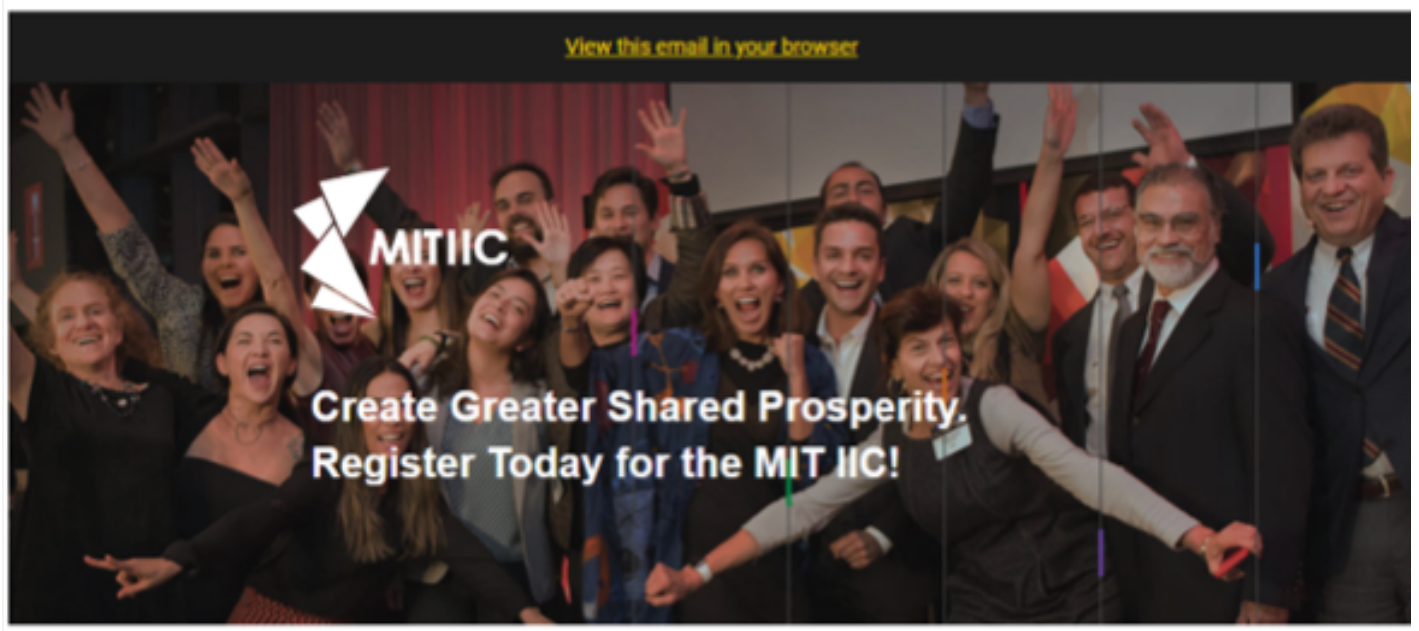

Hi "|FNAME|"

The MIT IIC is seeking innovative entrepreneurs with solutions to our 2019 Challenge. Win the opportunity to maximize the difference you are making in the world using tech for good!

The IIC is the flagship program of the MIT Initiative on the Digital Economy. annually supporting entrepreneurs who are using technology to create economic opportunity for all. Global Winners will receive the IIC's full support to solve the world's most pressing problems related to economic inclusion. In the last three years, the IIC has helped 100 organizations impact the lives of people around the world. View past winners.

We collaborate with like-minded organizations in five regions to select and celebrate sixty Regional Finalists from across the globe. Twenty Regional Winners will be invited to the Global Grand Prize Gala at MIT, where four Global Winners will be announced. Learn more about the llC.

\section{Registration Closes May 9.}

REGISTER NOW

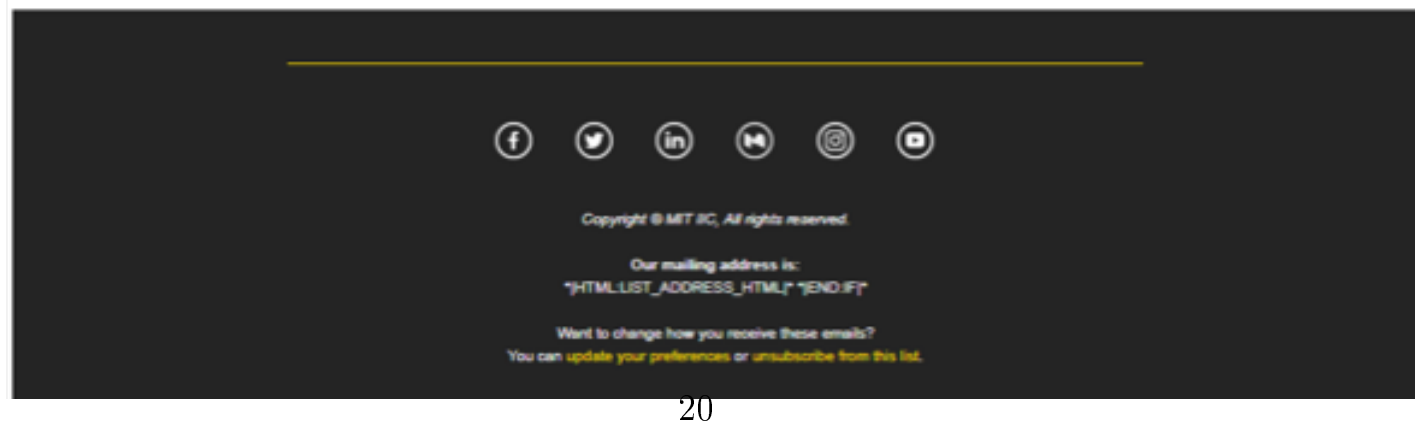


Figure A2: (c) Registration Stage Email Templates - Neutral Treatment

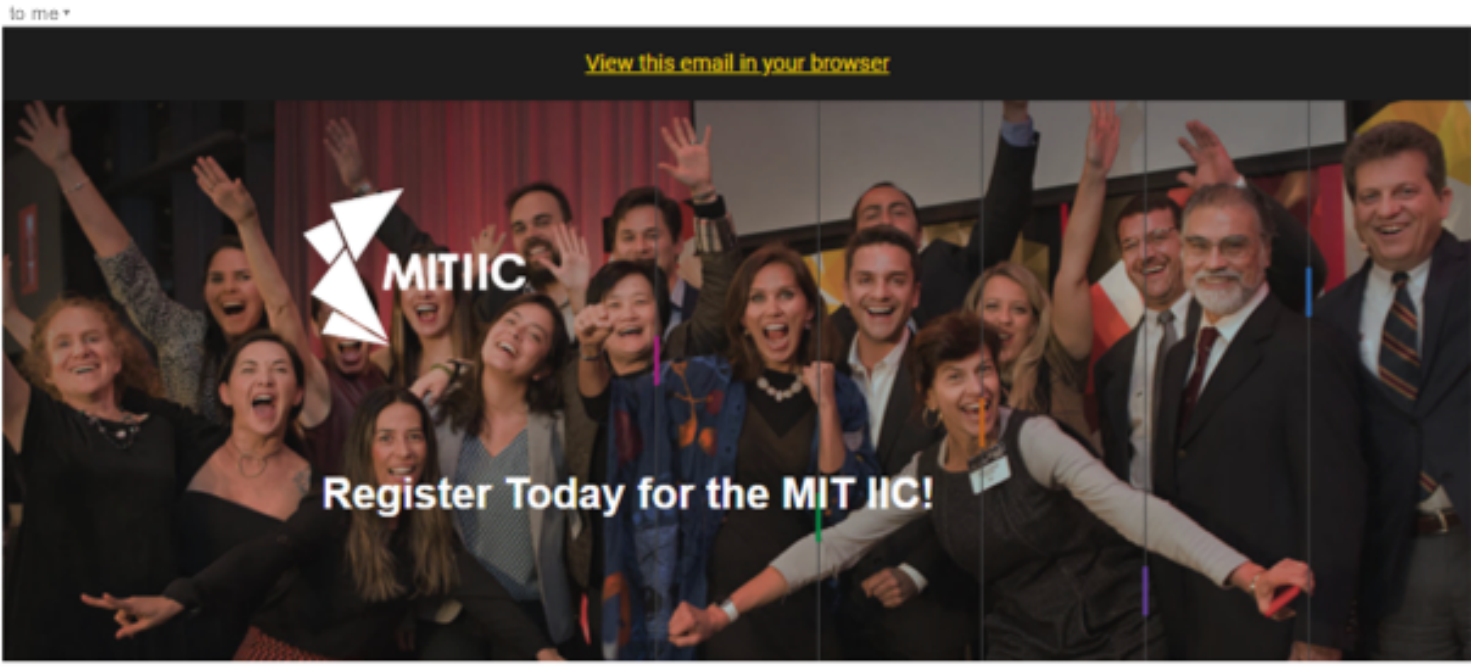

Hi *|FNAME|*,

The MIT IIC is seeking innovative entrepreneurs with solutions to our 2019 Challenge. Win by presenting your innovative tech solutions!

The IIC is the flagship program of the MIT Initiative on the Digital Economy, annually celebrating entrepreneurs who are using technology to create innovative solutions to global challenges. Global Winners will receive the award at the Global Grand Prize Gala at MIT. In the last three years, the IIC has awarded 100 organizations around the world. View past winners.

We collaborate with like-minded organizations in five regions to select and celebrate sixty Regional Finalists from across the globe. Twenty Regional Winners will be invited to the Global Grand Prize Gala at MIT, where four Global Winners will be announced. Learn more about the $\| C$.

\section{Registration Closes May 9.}

REGISTER NOW

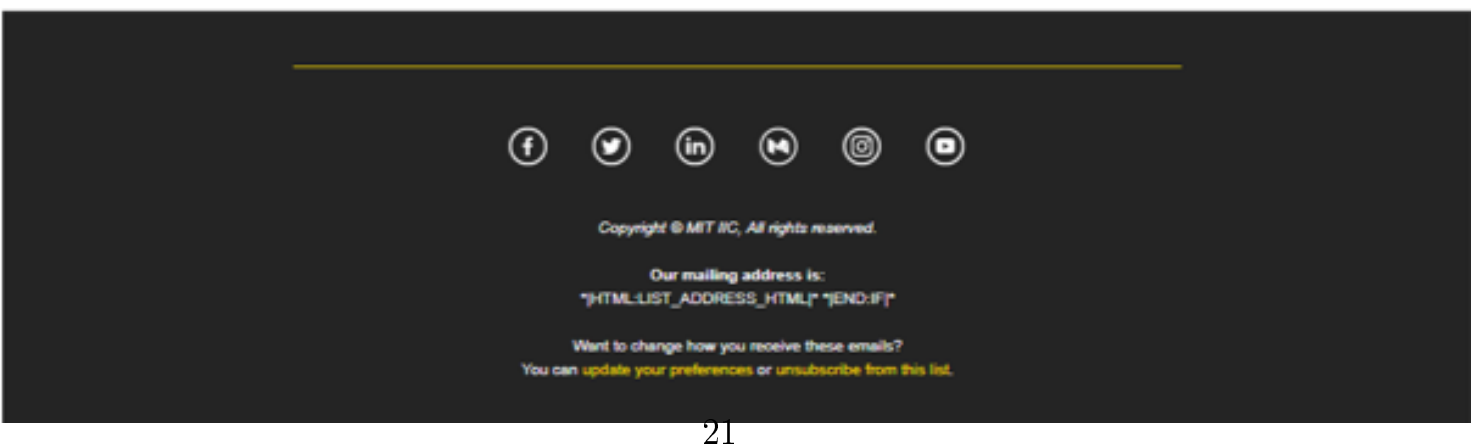




\section{Inclusive innovators are changing the world}

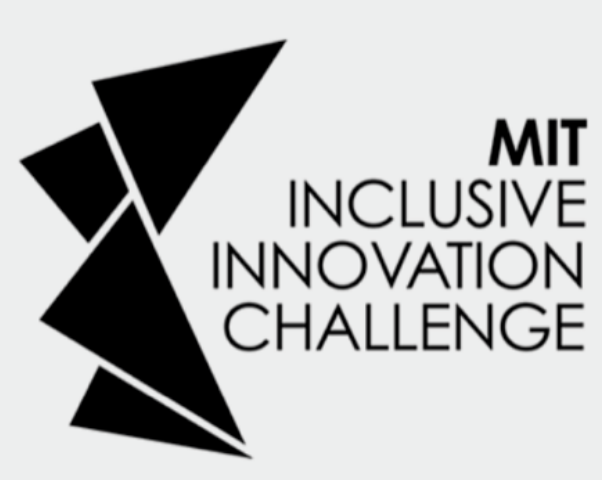

MIT is accelerating the best future of work solutions on the planet. The MIT IIC has, once again, launched its premier competition for technologyoriented entrepreneurs looking for mentorship, financial support, and exposure.

Registration only takes a few minutes and closes May 9th. 
Figure A4: (a) Application Stage Email Templates Type 1 - Money Treatment

More than $\$ 1.6 \mathrm{M}$ in Prize Money. Complete Your MIT IIC Application by MAY 23 क
MIT IIC cilcemil.edtip
to me.
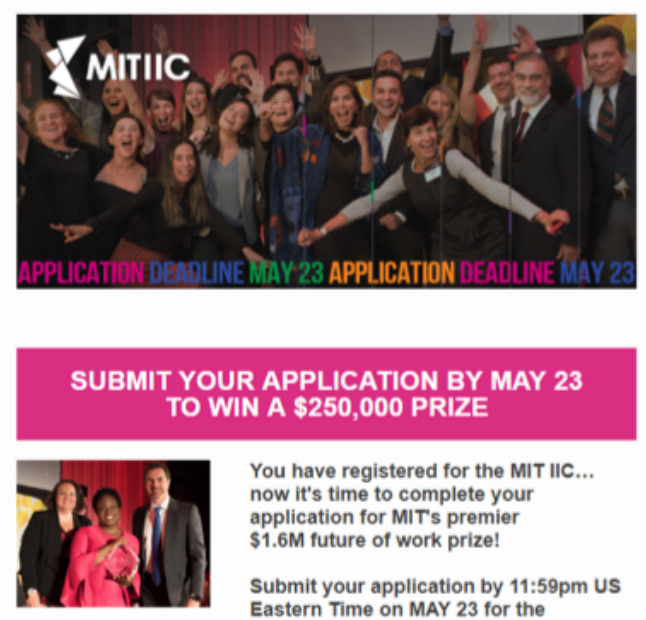

You have registered for the MIT IIC...

now it's time to complete your

application for MIT's premier

Submit your application by 11:59pm US

Submit your application by $11: 59 p m$
Eastern Time on MAY 23 for the

opportunity to receive a $\$ 250,000$ prize

and gain access to the MIT innovation

ecosystem, including potential

$$
\text { investors. }
$$

Complete your application today by logging in at nttoimitinclusiveinnovation com

All appicants receive feecback from leading global policymakers, funders, technologists, and academics in the region, regardiess of finalist status.

Questions?

EMAIL THE IIC TEAM

MIT IIC 2018 WINNERS

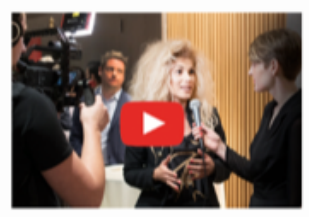

Meet the 2018 MIT IIC Winners

Winning the IIC is a game changer, but dont take our word for it. Meet last years Grand Prize Winners at the Global Grand Prize Gala at MIT.

UPCOMING IC EVENTS

IIC Giobal Grand Prize Gaid

September - October Darmstadt. Germany Kaohsiung.

Tawan; Africa TRD
MORE INFO

November 21 - MIT Samberg Conterence Cambridge. MA

Cambridge, MaA
MORE INFE.

FOLLOW US

(†) (-) (2) (10) (4) (ㅇ) (2)

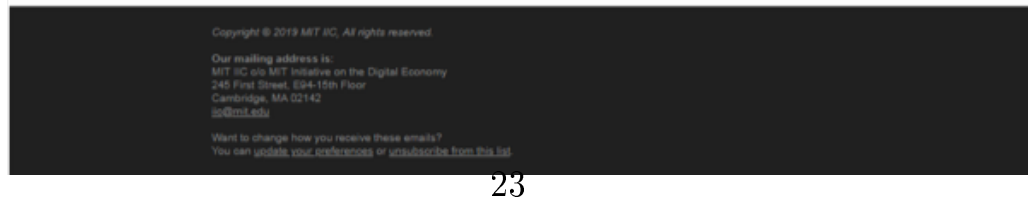


Figure A4: (b) Application Stage Email Templates Type 1 - Social Treatment

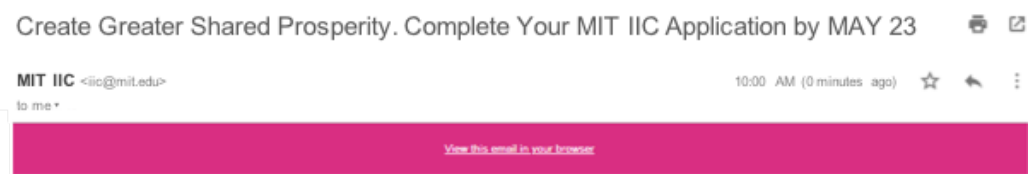
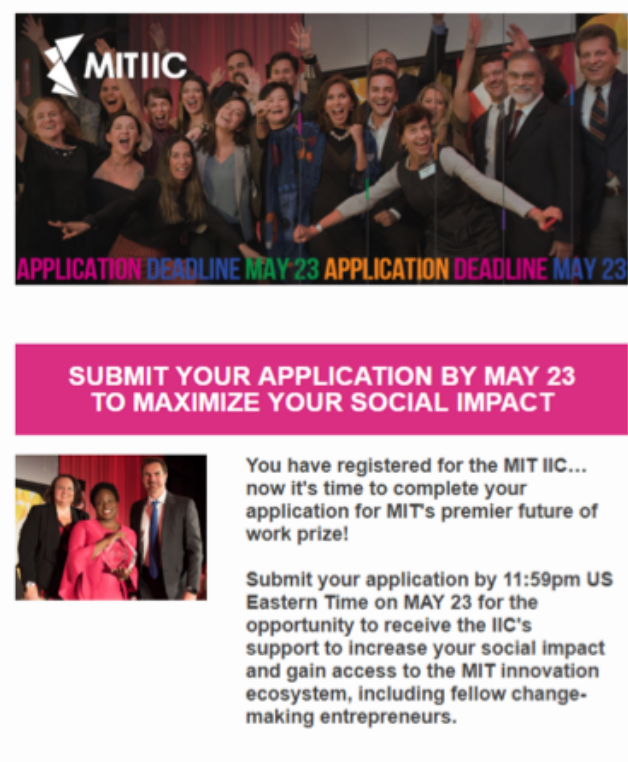

Complete your application today by logging in at nttp:ïmitinclusiveinnovation com

All appilcants receive feedback trom leading global policymakers, funders, technologists. and academics in the region, regardiless of finalist status.

Questions?

EMAIL THE IIC TEAM

\section{MIT IIC 2018 WINNERS}

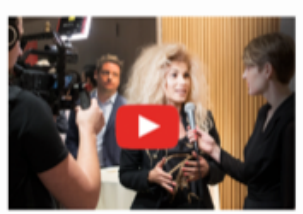

Meet the 2018 MIT IIC Winners

Winning the IIC is a game changer, bue don't take our word for ic. Meet last years Grand Prize Winners at the Giobal Grand Prize Gala at MIT

\section{UPCOMING IIC EVENTS}

IIC Regianal Celebrations September - October

Toronto Ontario . Kaohsung. Taiwan: Africa
MORE INFO
IIC Global Grand Prize Gals

November 21 - MIT Samberg Conference Cambrigge, MA

\section{FOLLOW US}

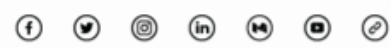


Figure A4: (c) Application Stage Email Templates Type 1 - Neutral Treatment

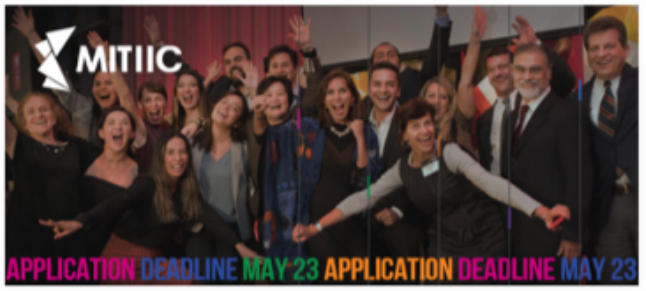

\section{SUBMIT YOUR APPLICATION BY MAY 23}

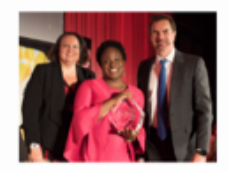

You have registered for the MIT IIC.. now it's time to complete your

application for MIT's premier future of work prize!

Submit your application by 11:59pm US

Eastern Time on MAY 23 for the

opportunity to receive an award from

MIT and gain access to the

MIT innovation ecosystem.

Complete your application today by logging in at $\mathrm{nttp} / \mathrm{imitinclusiveinnovation} \mathrm{com}$

All applicants recelve feedback from leading global policymakers, funders, technologists. and academics in the region, regarcless of finalist status

Questions?

\section{EMAIL THE IIC TEAM}

\section{MIT IIC 2018 WINNERS}

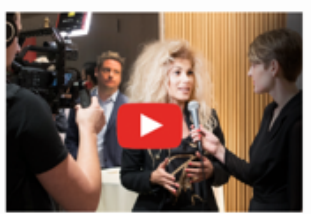

Meet the 2018 MIT IIC Winners

Winning the IIC is a game changer, but don't take our word for it Meet last years Grand Prize Winners at the Global Grand Prize Gala at MIT.

\section{UPCOMING IIC EVENTS} IIC Regional Celebrations
September-October Mexico Ciry, Mexico, Toronto, Ontario. Garmstadt, Germany, Kaohsiung. Tawan: Africa Th
MORE INFO
IIC Global Grand Prize Ga: November 21 - MIT Samberg Conference Center
Cambridge, MA
MORE INFO

\section{FOLLOW US}
(4) (-) (9)
(iin)
$\oplus$ (ㅇ)

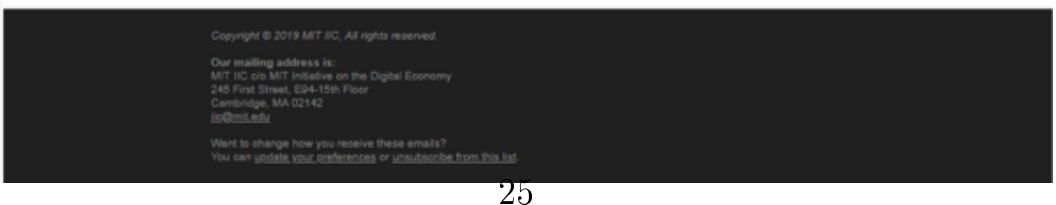


Figure A5: (a) Application Stage Email Templates Type 2 - Money Treatment
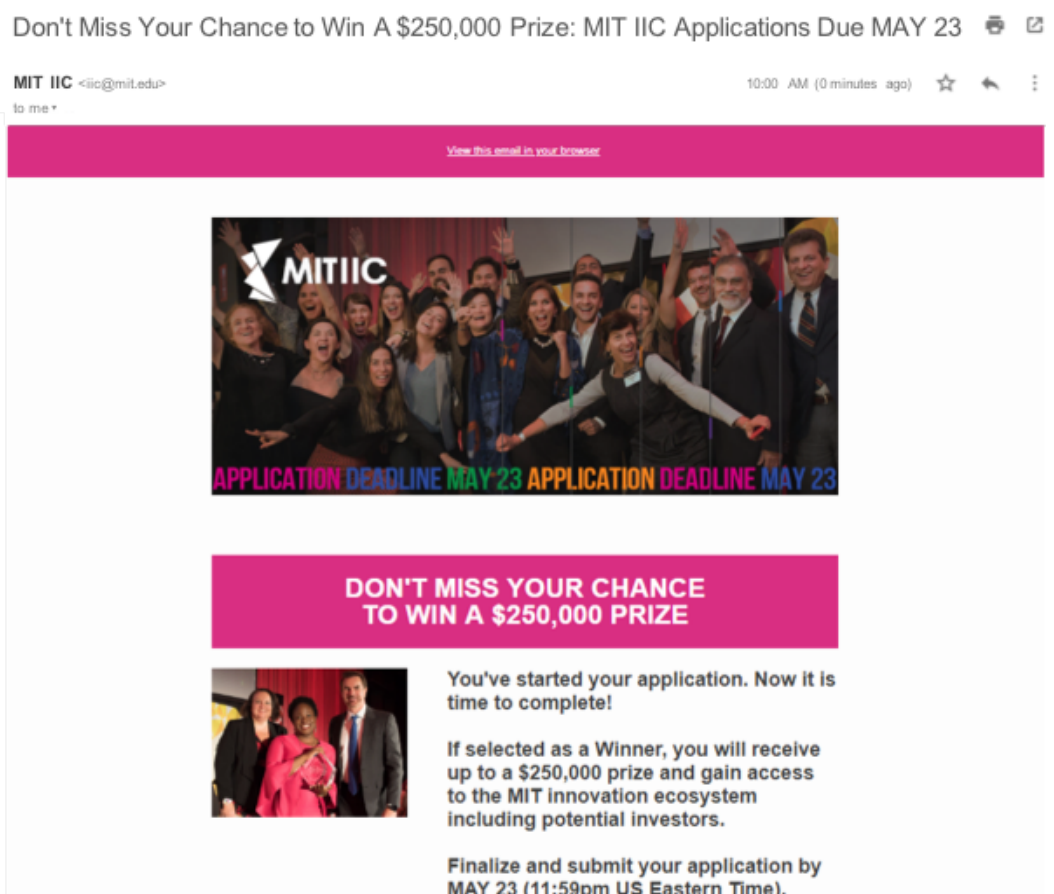

Complete your application today by logging in at http/imitinclusiveinnovation com

All applicants receive feedback trom leading global policymakers, funders, technologists. and academics in the region, regardeless of finalist status.

Questions?

EMAIL THE IIC TEAM

MIT IIC 2018 WINNERS

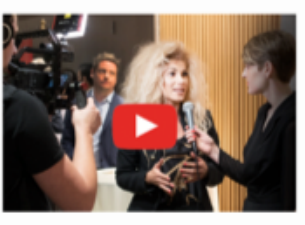

Meet the 2018 MIT IIC Winners

Winning the IIC is a game changer, but don't take our word for it. Meet last year's Grand Prize Winners at the Global Grand Prize Gala at MIT

\section{UPCOMING IIC EVENTS}

IIC Regional Celeorations Mexico City, Mexico, Toronto, Ontario, Darmstadt, Germany, Kaohsiung. Talwan, Africa ToD

IIC Global Grand Prize Gala

Cambridge, MA
MORE INFO

\section{FOLLOW US}

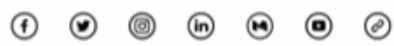

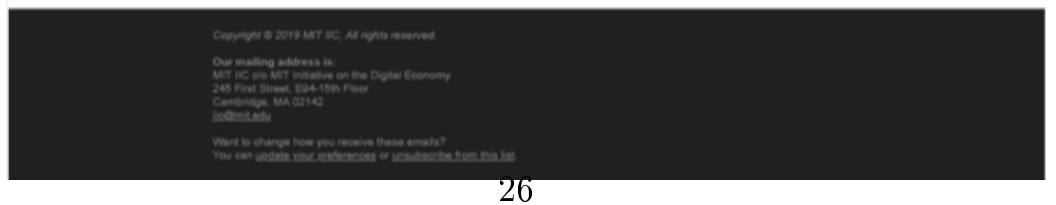


Figure A5: (b) Application Stage Email Templates Type 2 - Social Treatment

Don't Miss Your Chance to Maximize Your Social Impact: MIT IIC Applications Due MAY 23
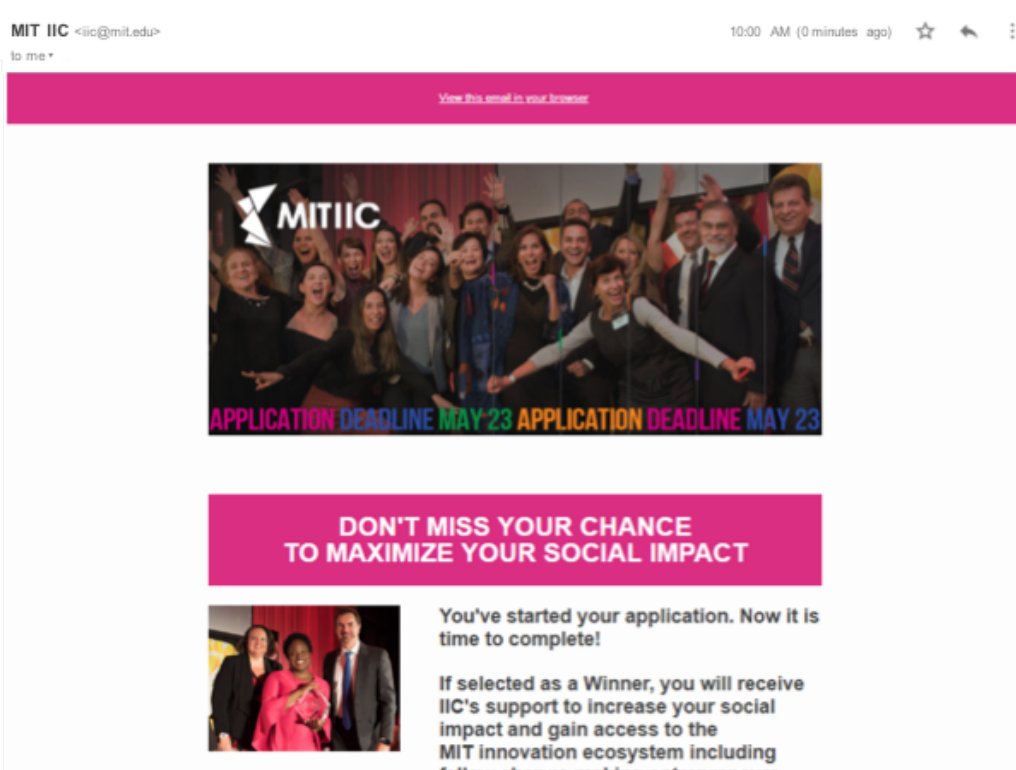

DON'T MISS YOUR CHANCE

You've started your application. Now it is time to complete!

If selected as a Winner, you will receive

IIC's support to increase your social

impact and gain access to the

MIT innovation ecosystem including fellow change-making entrepreneurs.

Finalize and submit your application by MAY 23 (11:59pm US Eastern Time).

MIT IIC 2018 WINNERS

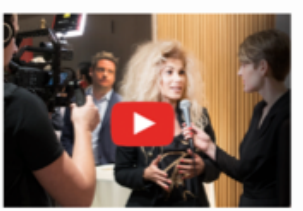

Meet the 2018 MIT IIC Winners

Winning the IIC is a game changer. DU: cont take our word for 2 . Meet last years Grand Prize Winners at the Glooal Grand Prize Gala a MiT.

\section{UPCOMING IC EVENTS}

IIC Regional Celebrations Oarnstant, Germas, Toronto, Ontario, Talwan: Africa TBO
MORE INFO
IIC Globar Grand Prize Gala November 21 - Mit Samberg Conference Cambridge, MA
MORE NFO

\section{FOLLOW US}

() (ㄱ) (2) (in) () (ㅇ) (ㅇ)

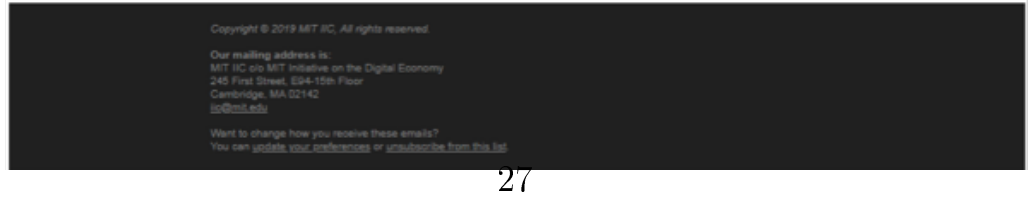


Figure A5: (c) Application Stage Email Templates Type 2 - Neutral Treatment
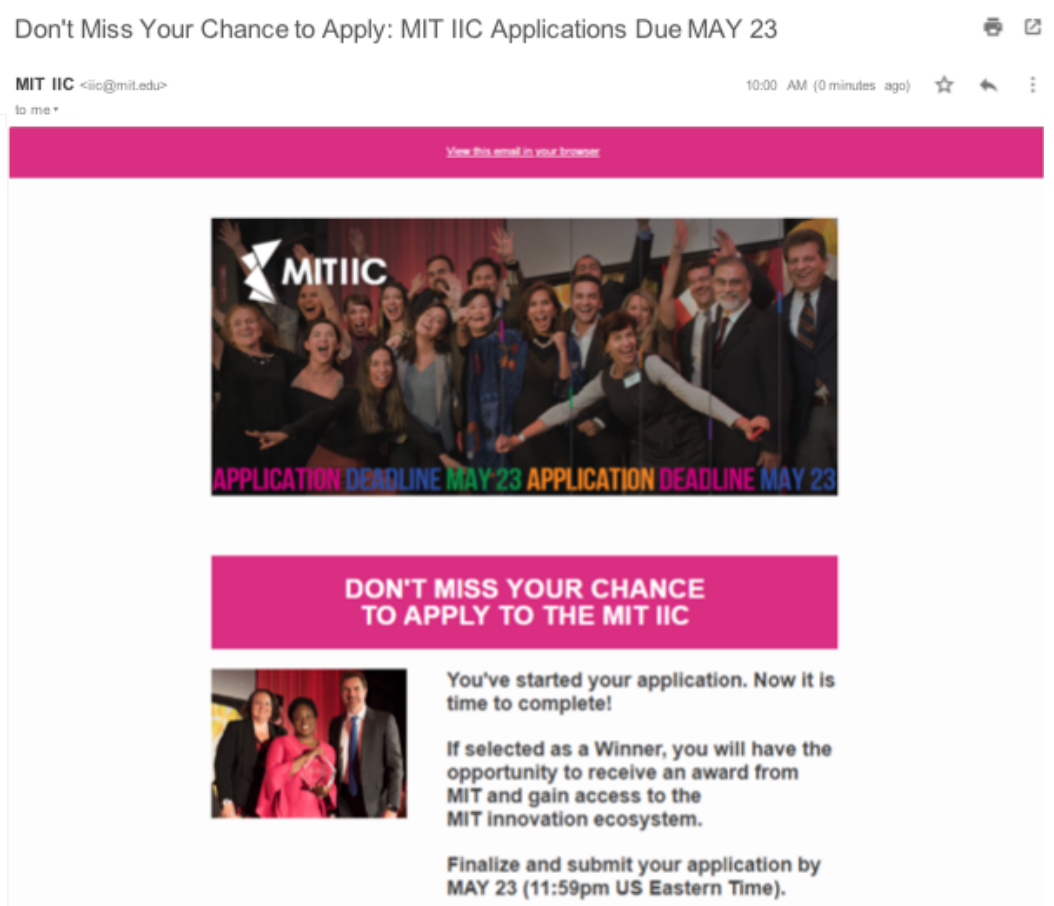

Complete your application today by logping in at Hiteliminnclusiveinnevation com

All applicants receive feecback from leading global polkymakers, funders, technologists. and academics in the region. regardiess of fnalst statis

Questions?

EMAIL THE IIC TEAM

\section{MIT IIC 2018 WINNERS}

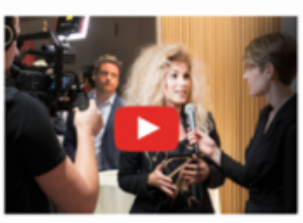

Meet the 2018 MIT IIC Winners

Whning the IIC is a game changer but dont take our word for $\mathrm{R}$. Meet last years Grand Prize Winners at the Glooal Grano Prize Gala at Mir.

\section{UPCOMING IIC EVENTS}

IIC Regional Celebrations Mexico City, Mexica, Toronto, Ontanio; parmstact, Germany, Kaohsiung. Tawan; Africa TBO
MORE INFE MC Giooar Grand Prize Gala
November 21 - MIT Samberg Conference Cambridge, ma MOPFINFO

\section{FOLLOW US}

(†) (ㄷ) (2) (10) (-) () (ㅇ)

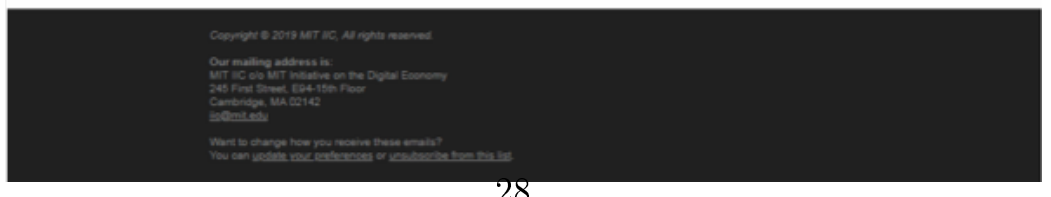


Figure A6: (a) Application Stage Email Templates Type 3 - Money Treatment

You Can't Win \$250,000 If You Don't Comp(l)ete! MIT IIC Applications Due MAY 23
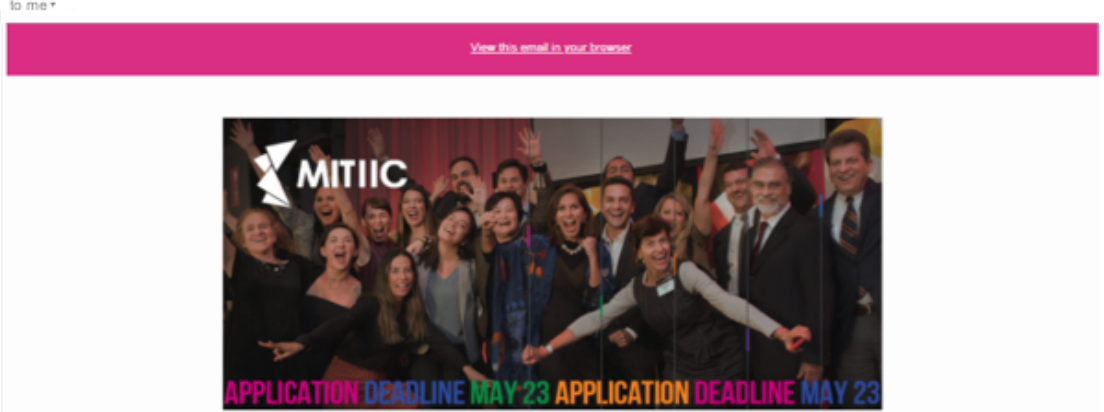

Did you know that winners receive up to a $\$ 250,000$ prize and gain access to the MIT innovation ecosystem, including potential investors?

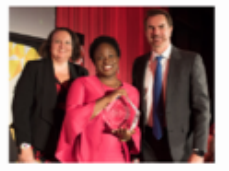

You're so close. Don't let this opportunity to win the money prize pass you byl

Finalize and submit your application by

11:59pm US Eastern Time, MAY 23

at MITinclusiveinnovation com.

All applicants receive feedback from leading global policymakers, funders technologists, and academics in the region, regardless of finalist status.

Questions?

\section{EMAIL THE IIC TEAM}

\section{MIT IIC 2018 WINNERS}

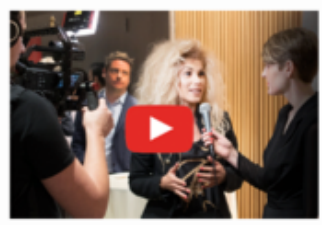

Meet the 2018 MIT IIC Winners

Winning the IIC is a game changer, but dont take our word for it. Meet last year's Grand Prize Winners at the Global Grand

Prize Gata at MIT.

\section{UPCOMING IIC EVENTS}

IIC Regional Celebrations
September - October

Mexico City, Mexico, Toronto, Canada, Darmstadt, Germany, Kaohsiung, Taiwan: Africa MOREINFO

MC Giobal Grand Prize Gaid November 21 - MIT Samberg Conterence Center
Cambridge, MA Cambinge,
MOREINFO

\section{FOLLOW US}
() () (ㄱ) (in) () () ()

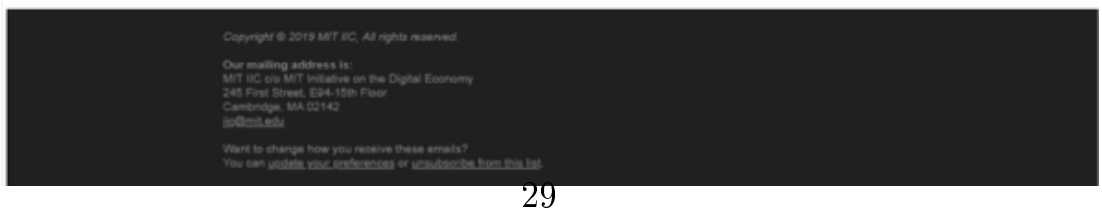


Figure A6: (b) Application Stage Email Templates Type 3 - Social Treatment
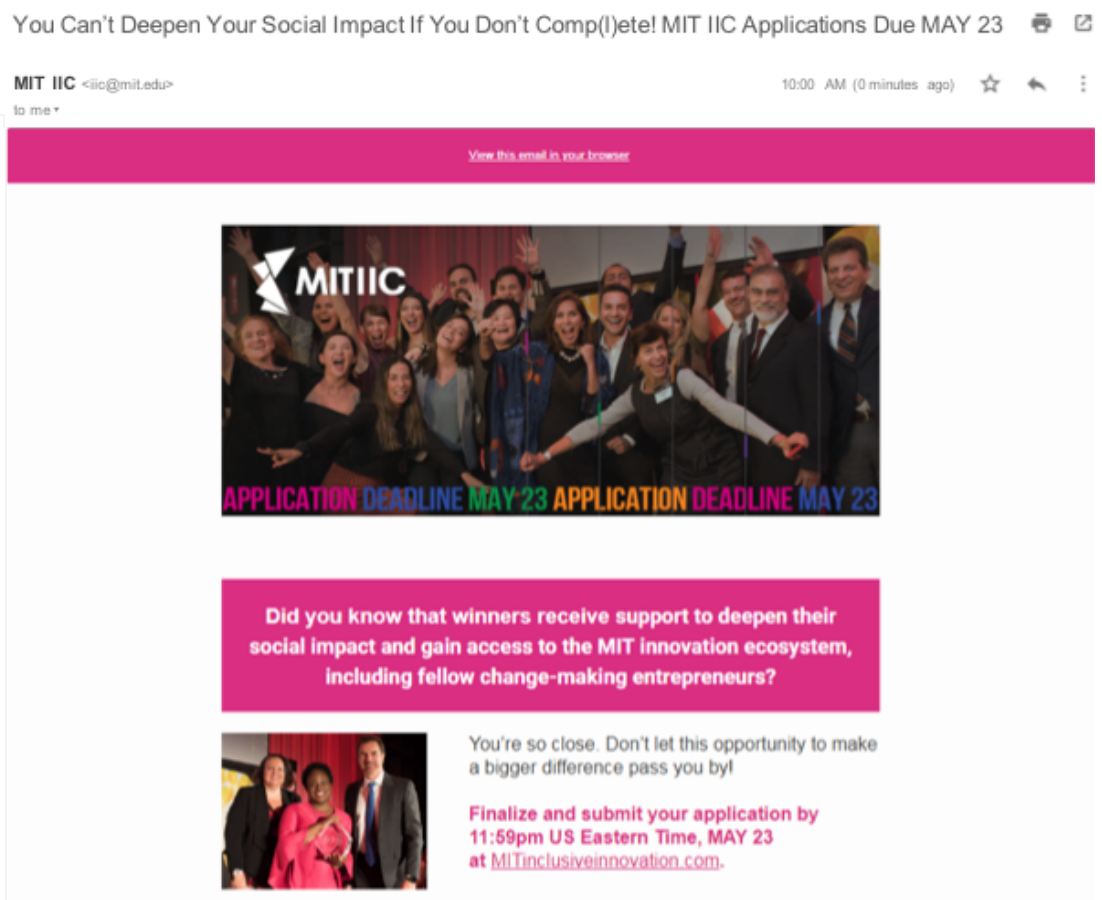

You're so close. Don't let this opportunity to make a bigger difference pass you byl

Finalize and submit your application by

11:59pm US Eastern Time, MAY 23

at Milinclusiveinnovation com.

All applicants receive feedback from leading global policymakers, funders, technologists, and academics in the region, regardless of finalist status.

Questions?

\section{EMAIL THE IIC TEAM}

\section{MIT IIC 2018 WINNERS}

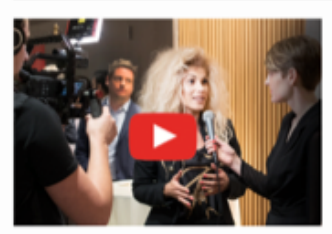

Meet the 2018 MIT IIC Winners

Winning the IIC is a game changer, but dont take our word for $\mathrm{k}$. Meet last year's Grand Prize Winners at the Global Grand Prize Gala at MIT.

\section{UPCOMING IIC EVENTS}

IIC Regional Celeobrations

September- Octooer

Mexico City, Mexico, Toronto, Canada Darmstadt, Germany, Kaohsiung, Taiwan: Africa
MOREINFO
IIC Global Grand Prize Gaia November 21 - MiT Samberg Conference Center
Cambridge, MA Cambridge, MA

\section{FOLLOW US}
(†)
() (ㅇ) (in) () () (2)

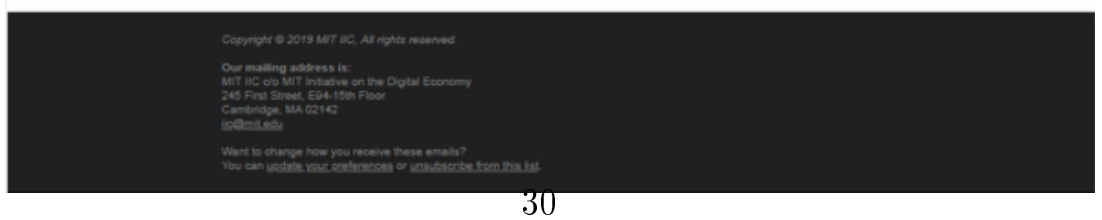


Figure A6: (c) Application Stage Email Templates Type 3 - Neutral Treatment

to me

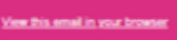

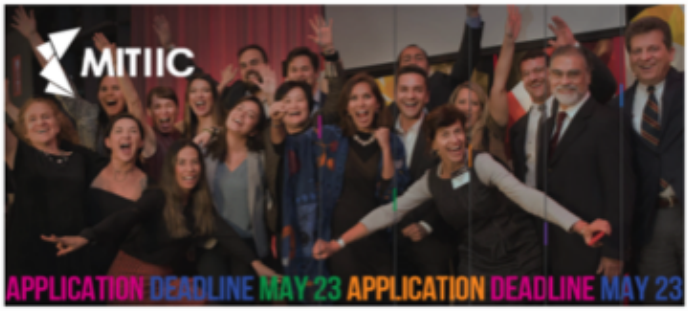

Did you know that winners receive an award from MIT and gain access to the MIT innovation ecosystem?

You're so close. Don't let this opportunity pass you byl

Finalize and submit your application by 11:59pm US Eastern Time, MAY 23

at Mirinclusivernovation com.

All applicants receive feedback from leading global policymakers, funders, technologists, and academics in the region, regardless of finalist status.

Questions?

EMAIL THE IIC TEAM

MIT IIC 2018 WINNERS

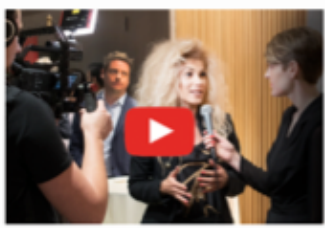

Meet the 2018 MIT IIC Winners

Winning the IIC is a game changer, but cont take our word for it. Meet last years

Grand Prize Winners at the Global Grand Prize Gala at MiT.

\section{UPCOMING IIC EVENTS}

IIC Regional Celebrations

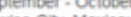

Tomonto Canadi:

Darmstadt. Germany, Kaonsiung Tavar; Africa TBD

IIC Gloobal Grand Prize Gala Center

HORE ANFO

Cambinge, MA

MORE INFO

\section{FOLLOW US}
(†) ()
(in)
() (2)

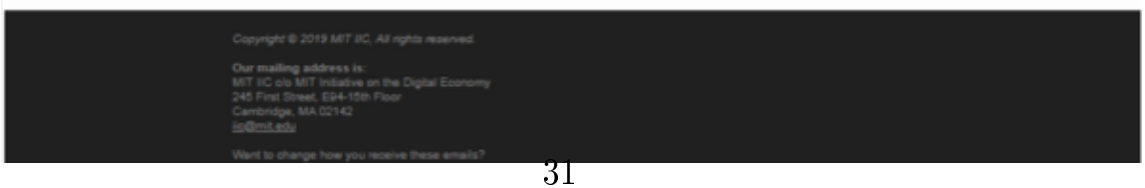


Figure A7: Registration Round - Extensive Margin by Gender

\section{Probability of Click by Gender and Treatment}

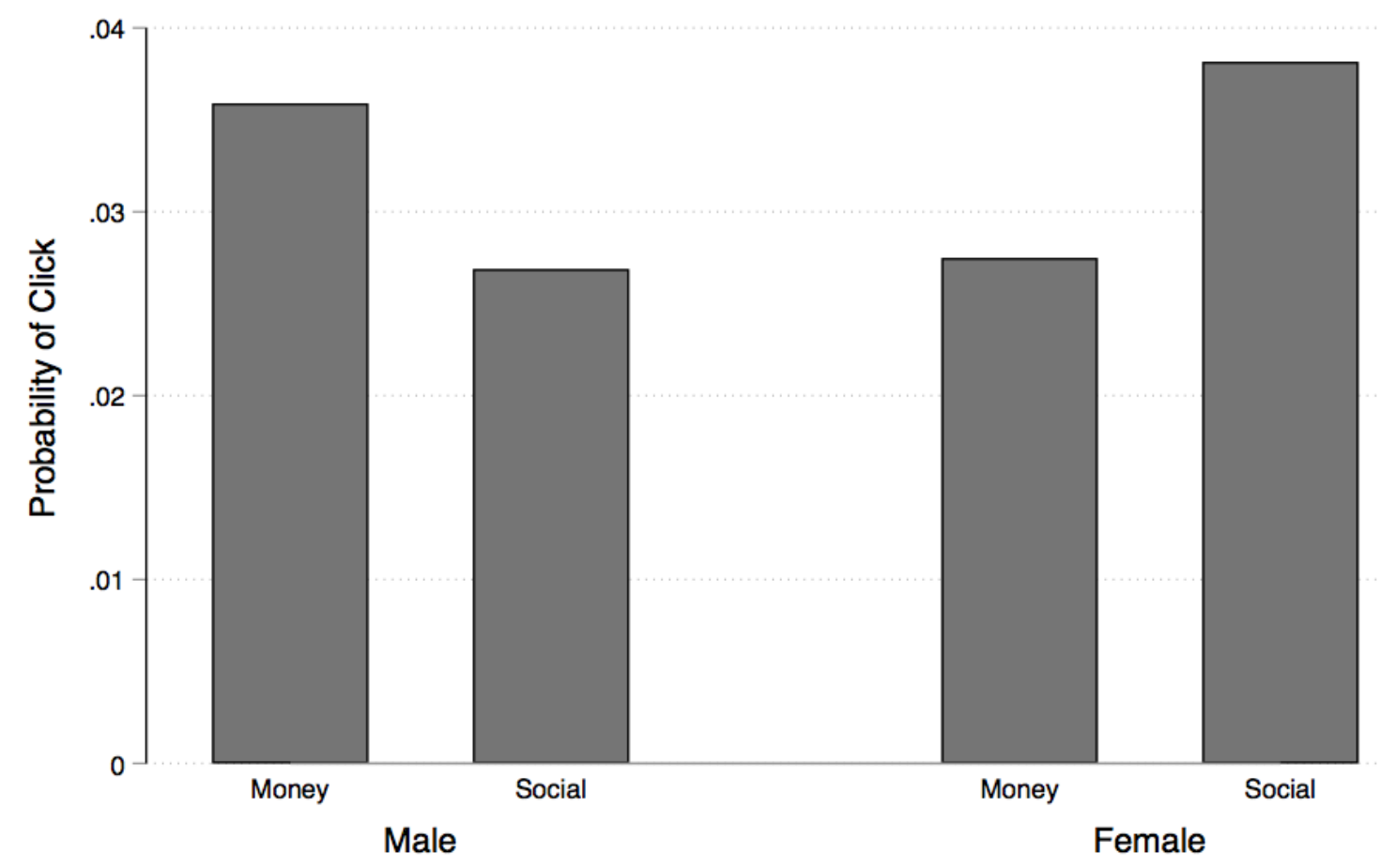

